\title{
Management Earnings Forecasts, Information Asymmetry, and Liquidity: An Empirical Investigation
}

Article in SSRN Electronic Journal · July 2007

DOI: $10.2139 /$ ssrn.994960

CITATIONS

6

1 author:

Mikhail Pevzner

University of Baltimore

40 PUBLICATIONS 236 CITATIONS

SEE PROFILE
READS

51

Some of the authors of this publication are also working on these related projects:

Project

Crowdfunding View project

Project

GOODWILL IMPAIRMENT-Usage of goodwill impairment by investors View project

All content following this page was uploaded by Mikhail Pevzner on 04 April 2014. 


\title{
Management Earnings Forecasts, Information Asymmetry, and Liquidity: An Empirical Investigation
}

\author{
Mikhail Pevzner
}

\author{
School of Management \\ George Mason University \\ 4400 University Dr MS-5F4 \\ Fairfax VA 22030 \\ Email:mpevzner@gmu.edu
}

July 2007

\begin{abstract}
This study investigates (1) whether forecasting firms have lower liquidity prior to the issuance of a management-earnings forecast than non-forecasting firms and (2) whether forecasting earnings has a persistent affect on a firm's liquidity. I find that, first, forecasting firms have greater liquidity in the period prior to a forecast. Second, while issuing forecast increases liquidity in over short windows, this effect is not significant over longer windows. Third, initiating or ceasing the issuance of earnings forecasts has no significant long-term effect on the firm's liquidity. Combined, these results suggest that management earnings forecasting decision does not appear to be driven by liquidity-improvement goals, and that management earnings forecasts do not appear to strongly affect firms' liquidity.
\end{abstract}

Keywords: Management Earnings Forecasts, Information Asymmetry, Liquidity

Acknowledgements: I owe special thanks to my dissertation committee: Richard Frankel, (chair), Guy Genin, Edward Greenberg, Ohad Kadan, Ron King, Lubomir Litov, and Tzachi Zach. My special thanks also goes to accounting workshop participants at Fordham University, George Mason University, University of Illinois in Chicago, University of New Hampshire, Santa Clara University, University of Texas at Arlington, and Washington University in Saint Louis. My deep thanks go to Financial Markets Research Center at Owen School of Business at Vanderbilt University for providing market microstructure data. 


\section{Introduction}

This study examines (1) whether forecasting firms have lower liquidity prior to the issuance of a management-earnings forecast than non-forecasting firms and (2) whether forecasting earnings has a persistent affect on a firm's liquidity. These research questions are important for two reasons. First, prior work indicates that firms issue management forecasts to improve their current liquidity, whereas more recent evidence suggests that, on average, forecasting firms are more liquid than nonforecasting firms. Second, prior work does not address the persistence of management earnings forecasts' liquidity effect and thus does not establish whether management earnings forecasting has significant cost of capital implications.

Market microstructure theory suggests that higher information asymmetry is associated with lower liquidity (Copeland and Galai (1983), Glosten and Milgrom (1986)). Firms can reduce information asymmetry and increase liquidity through the disclosure of their value-relevant information (Diamond and Verrecchia (1991), King et al. (1991)). Literature suggests that management earnings forecasts reduce firms' current information asymmetry and improve their liquidity because high information asymmetry and lower liquidity are costly. In particular, using a limited sample of 179 management earnings forecasts, Coller and Yohn (1998) reach two conclusions for the period 1989-1992: 1) Forecasting firms have higher pre-forecast bid-ask spreads, and 2) management earnings forecasts reduce these bid-ask spreads. This research implies that firms forecast earnings to improve liquidity. However, more recent research documents that forecasting firms are more liquid than non-forecasting firms. 
For example, Brown et al. (2005) shows that during the 1990s, forecasting firms were larger and had a higher analyst following and greater institutional ownership. Such firms usually have higher quality disclosure policies, such as annual report and earnings announcement disclosures, and are usually more liquid (Hutton et al. (1999)). This research raises the question of whether improving liquidity is a primary goal of management earnings forecasting policies. Therefore, I examine forecasting firms in the pre-forecasting period during the 1990s to determine whether they are less liquid than non-forecasting firms, and whether these firms' earnings forecasting is associated with persistent improvements in liquidity.

Because more liquid stocks have lower cost of capital, more persistent effects of management earnings forecasts on liquidity are also associated with stronger management earnings forecasts' effects on forecasting firms' cost of capital (Diamond and Verrecchia, 1991). More persistent liquidity improvements could occur if 1) informed investors' information advantage is driven by their advanced knowledge of the forecasted period's earnings number, and 2) if firms' disclosures other than earnings forecasts (e.g. press releases, conference calls, or quarterly 10-Q disclosures) do not substitute for information contained in management earnings forecasts. Empirical evidence suggests that forecasting firms have rich disclosure policies in place (Brown et al. (2005)), and therefore that the incremental liquidity effect of management earnings forecasts need not be economically significant. Hence, I extend Coller and Yohn by examining the persistence of forecasting firms' liquidity improvements following management earnings forecasts. 
Using a sample of 4,202 quarterly management earnings forecasts issued between 1994 and 2003, I compare the liquidity levels of forecasting firms and nonforecasting firms in the pre-forecast period. I then compare the changes in information asymmetry of forecasting and non-forecasting firms around the management forecast date over both short and long measurement windows. In addition to quoted bid-ask spreads, I use quoted depths, Amihud Illiquidity, and trading volume as information asymmetry and liquidity proxies. I use depths as another information asymmetry metric because studies in market microstructure suggest that both bid-ask spreads and depths have to be used to fully describe firms' liquidity (Lee et al. (1993), Dupont (2000)). I also use Amihud Illiquidity as another information asymmetry measure, proxying for firms' Kyle's Lambda (Kyle, 1986). Finally, some studies (e.g. Leuz and Verrecchia (2000)) suggest that greater trading volume is correlated with higher liquidity, and therefore I include trading volume as an additional liquidity metric.

To better understand persistence effects of management earnings forecasts, I also investigate whether initiation (cessation) of a forecasting policy is associated with long-term liquidity increases (decreases). Leuz and Verrecchia (2000) show that firms' commitments to higher quality future mandatory disclosure policies result in improved liquidity. I perform the initiation and cessation tests because disclosure theory suggests that the effects of disclosure policy changes on liquidity in these settings can be persistent (Core, 2001, Leuz and Verrecchia, 2000). Initial forecasts are an indicator of disclosure policy change because current management earnings forecasting is a predictor of future management earnings forecasting (Brown et al. 
2005). The initiation and cessation tests use quoted bid-ask spreads, depths, Amihud Illiquidity, and trading volume as liquidity metrics.

By focusing on the liquidity improvement effect of management earnings forecasting, this paper contributes to the literature on the determinants of the management forecasting of earnings. By examining the persistence of management forecasts' liquidity effect, I contribute to the literature on the consequences of management earnings forecasting. Also, by directly examining the forecast cessation liquidity effects, I extend the recent literature on the consequences of forecast cessation (Chen et al. (2006), Houston et al. (2006)).

Empirical results. My findings indicate that forecasting firms are not less liquid than non-forecasting firms before management forecasts are issued. This result contrasts with that of Coller and Yohn. I also show that management earnings forecasts are associated with only short-term improvements in liquidity. I find only weak evidence for an association between the initiation of management earnings forecasts and reductions of information asymmetry and increases in liquidity. The study also does not find that management earnings forecast cessation is associated with subsequent increases in the information asymmetry levels and reductions in liquidity. Thus, my results suggest that forecasting policy does not strongly affect firms' future liquidity.

This study's results should be interpreted with caution in light of the known biases in market microstructure measures of information asymmetry that I use in my study (Callahan et al., 1997). Other limitations of my study are introduced by reliance on First Call database as a representative population of management earnings 
forecasts, the smaller sizes of samples used in my tests of liquidity effects of changes in firms' forecasting policy and by my reliance on First Call's CIG database coverage (or lack thereof) as an indicator of forecasting policy initiation or cessation.

\section{Motivation}

Finance theory suggests that information asymmetry is associated with lower stock liquidity and that lower stock liquidity takes the form of higher bid-ask spreads, lower depths, and higher information risk premiums. Lower liquidity, in turn, is associated with increases in firms' cost of capital (Diamond and Verrecchia (1991), Amihud (2002), Easley and O'Hara (2002)). Higher bid-ask spreads arise because market makers are uninformed and thus seek compensation for expected losses in trades with informed traders (Kim and Verrecchia (1994), Harris (2003)). Market makers increase bid-ask spreads so that their trade losses with informed investors are offset by trade gains with uninformed investors (Copeland and Galai (1983), Glosten and Milgrom (1986)). ${ }^{1}$ In addition to bid-ask spreads, market makers use depths to limit losses arising from trades with informed investors. Depths are quantities of shares that market makers are willing to trade at a given bid or ask price (Harris (2003)). When information asymmetry is high, a market maker could, to reduce her losses, either increase bid-ask spreads or reduce depths, or do both (Dupont (2000)). ${ }^{2}$ Hence,

\footnotetext{
${ }^{1}$ The component of bid-ask spreads arising as a result of information asymmetries is also known as the adverse selection component of the spread. Bid-ask spread also has an inventory component (compensation for un-diversifiable market-maker risk associated with holding a particular stock) and a trading commission component (Stoll (2000)).

2 For two reasons, market makers could find it undesirable to increase bid-ask spreads, especially when bid-ask spreads are already very high. First, market makers who are also specialists are obligated to provide reasonable bid-ask spreads for the specialist-based stock exchanges, such as NYSE or AMEX (Harris (2003), page 497). Second, when market makers increase the spreads, they cause the
} 
depths capture an additional dimension of information asymmetry and liquidity, and should, for a more complete analysis of liquidity, be used along with bid-ask spreads (Lee et al. (1993), Heflin et al. (2005)). Higher information asymmetry also results in a higher information risk premium. When new information arrives, uninformed traders are unable to rebalance their portfolios in a timely fashion because only informed investors observe new information arrival. Hence, uninformed traders demand additional risk premium for losses incurred as a result of untimely portfolio rebalancing (Myers and Majluf (1983), Rock (1986), Easley et al. (2002)).

Disclosure reduces information asymmetry and increases liquidity via two channels. First, it levels the current "information playing field" between informed and un-informed investors by communicating private information hitherto unknown to uninformed investors (Lev (1989)). Second, a commitment to future greater disclosure levels reduces incentives for future collection of private information and thus increases liquidity ex-ante (Leuz and Verrecchia (2000)). Management earnings forecasts are a special type of disclosure, and this paper focuses on their role in reducing firms' information asymmetry and improving their liquidity.

The empirical accounting literature identifies several goals of management earnings forecasting. These goals are (1) reducing information asymmetry and improving liquidity by issuing timely and credible management earnings forecasts (King et al. (1991), Frankel et al. (1995), Marquardt and Weidman (1998), Coller and Yohn (1997)), Clement et al. (2003), Schrand and Verrecchia (2005)), (2) reducing litigation risk (Skinner (1994), Baginski et al. (2002), Soffer et al. (2000), Field et al. can instead lower the depths (Dupont (2000)). 
(2005)), (3) signaling managerial talent (Trueman (1986)) and developing a managerial reputation for forthcoming and timely disclosure (Graham et al. (2005)), and (4) maximizing managerial compensation and stock trading gains (Noe (1999), Nagar et al. (2003)). These goals share a common theme that firms forecast earnings to facilitate trading in their stocks by increasing firms' current or future liquidity and reducing forecasting firms' cost of capital.

In particular, using a sample of 179 quarterly management earnings forecasts issued during 1989-1992, Coller and Yohn find that forecasting firms have higher bid-ask spreads than the matched sample of non-forecasting firms prior to issuing a management earnings forecast. After a firm issues a management earnings forecast, forecasting firms' bid-ask spreads decrease, suggesting that 1) forecasting firms are less liquid than non-forecasting firms in the pre-forecast period, and 2) management earnings forecasts improve firms' liquidity.

However, characteristics of forecasting firms' during the 1990s are inconsistent with Coller and Yohn's conclusion that, prior to the management earnings forecast date, forecasting firms are less liquid than non-forecasting firms, and thus firms issue management forecasts to improve liquidity. Brown et al. (2005) show that forecasting firms are larger, have higher analyst following, and greater institutional ownership. Such firms have lower bid-ask spreads and higher depths (Roulstone (2001)). In addition, such firms maintain higher quality disclosure policies, in particular better quarterly $10-\mathrm{Q}$ and investor relations disclosure policies (Lang and Lundholm (1996), Hutton et al. (1999)), also suggesting that forecasting 
firms are more liquid than non-forecasting firms (Welker (1995), Heflin et al. (2005)). Hence, my first hypothesis is as follows:

H1: The pre-forecast period information asymmetry of forecasting firms is equal to pre-forecast period information asymmetry of non-forecasting firms.

Coller and Yohn's findings also show that forecasting firms' liquidity improves after management earnings forecasts are issued. Because Coller and Yohn document a bid-ask spreads reduction over nine trading days after the management earnings forecast date, it is unknown whether this liquidity improvement persists over a longer horizon. Such an understanding is important because longer liquidity improvements translate into stronger reductions in firms' cost of capital and thus facilitate trades in stocks of forecasting firms. Diamond and Verrecchia (1991) show that disclosure reduces information asymmetry and increases future liquidity. In Diamond and Verrecchia model, this liquidity improvement effect is more important for large uninformed institutional investors who are concerned about future liquidity of their holdings. Firms seek to attract institutional investors because higher institutional investor demand for firms' stocks leads to these stocks' price increases. Institutional investors are particularly concerned about future stock liquidity because they want avoid losses in their future liquidity trades in response to random liquidity shocks. Uninformed institutional investors are more likely to prefer stocks which are more liquid for longer periods of time because only short liquidity improvements limit these investors' ability to avoid losses in trades as a result of random liquidity 
shocks. Thus, the more persistent the effect of management earnings forecasts is on forecasting firms' liquidity, the greater will be the uninformed institutional investor demand for the forecasting firms' stocks and the lower will be their cost of capital. ${ }^{3}$

Management earnings forecasts could lead to permanent upward shifts in firms' liquidity if uninformed investors do not have other means of forming unbiased earnings expectations. However, these liquidity effects could be also small because firms' liquidity is predominantly influenced by its other accounting and disclosure policies, such as firms' accounting quality (Francis et al. (2005)). Thus, management earnings forecasts are more likely to lead to temporary decreases in information asymmetry and increases liquidity, for example, due to unexpected economic shocks or undue analyst optimism (Cotter et al. (2006)). Hence, my next hypothesis (in the alternative form) is as follows:

H2: Management earnings forecasts are not associated with long-term reductions in information asymmetry.

When a forecasting firm initiates a forecasting policy, the effects of management earnings forecasts on liquidity could be more persistent. Brown et al. (2005) show that a management forecast issued in the prior quarter is a significant predictor of management earnings forecast in the current quarter. Thus, by initiating a forecasting policy, a forecasting firm also credibly reveals to the market that it will forecast earnings in the future. Such a commitment is expected to be associated with

\footnotetext{
${ }^{3}$ Consistent with institutional investor demand for future liquidity, Ajinkya et al. (2005) find that forecasting firms with higher institutional ownership tend to forecast earnings more frequently.
} 
ex-ante increases in firms' liquidity because (1) un-informed investors "reward" initiating firms for lesser levels of future uncertainty about these firms' performance, and (2) a commitment to future disclosure reduces the incentive to search for private information because the rewards from such searches are likely to be lower (Leuz and Verrecchia, 2000). However, management earnings forecast initiation will only have similar strong ex-ante liquidity effects if a commitment to greater forecasting 1) significantly expands firms' existing disclosure policies, and 2) uninformed investors believe that a forecasting firm will not renege on this commitment in the future.

As previously discussed, in addition to management earnings forecasting policies, forecasting firms are likely to have strong disclosure policies, thus reducing the effects of management earnings forecasts on firms' liquidity. Also, as opposed to a commitment to expanded mandatory disclosure policy (which make it costly for a firm to switch to a lower disclosure quality regime), management earnings forecasting is voluntary. A firm may be able to discontinue forecasting without bearing strong penalties. Uninformed investors thus do not necessarily consider a commitment to greater forecasting to be valuable and do not reward forecasting firms with higher liquidity levels. Hence, my next hypothesis (in the alternative form) is as follows:

H3: Management forecast initiation is not associated with long-term information asymmetry decreases.

If initiating earnings forecasting has a positive liquidity effect, then cessation of forecasting policy can have a negative liquidity effect. Management earnings 
forecasting cessation breaks the prior disclosure commitment, increases the expected gains from information search and thus increases firms' information asymmetry levels. In addition, absence of management earnings forecasts increases uninformed investors' uncertainty about firm performance because analysts rely on firms' management earnings forecasts in making their forecasts (Baginski and Hassel (1990)). Prior research thus finds that management forecast cessation is associated with subsequent increases in analyst forecast dispersion and in magnitudes of analyst forecast errors, and with losses of analyst following (Houston et al. (2006), Chen et al. (2006)). Greater analyst forecast dispersion and lower analyst accuracy and following likely leads to decreases in liquidity of stopping firms (Roulstone, 2001). Thus, my final hypothesis (in the alternative form) is as follows:

H4: Management forecast cessation is not associated with long-term information asymmetry increases.

\section{Sample selection and research design}

\subsection{Sample selection.}

Sample selection for testing Hypotheses 1-2.

I obtain management earnings forecasts data for 1994-2003 from the First Call Company Issue Guidance (CIG) database. To be included in the sample, forecasting firms must also have Market Microstructure database coverage ${ }^{4}$, CRSP and Compustat data available. These sample selection restrictions result in 12,207

\footnotetext{
${ }^{4}$ This is a database of average intra-day liquidity metrics developed at Financial Markets Research Center at Owen School of Business in Vanderbilt University. This database's estimates are based on intra-day data provided by TAQ (Trades and Quotes) database.
} 
management forecasts. Panel A of Table 1 describes details of sample selection procedure. $^{5}$

I construct a matched sample of 12,207 non-forecasting firms based on the two-digit SIC code, market value of equity in the quarter preceding the management forecast date, and on same fiscal year end. Non-forecasting firms must meet two conditions: 1) They cannot have any management forecasts issued in the 12 months prior to the matched forecasting firms' management earnings forecast date, and 2) they have to be covered by Compustat and CRSP, and Market Microstructure database.

Sample selection for testing Hypothesis 3 (initiating firms only):

To obtain a sample of management forecast initiations, from the CIG database, I select all (quarterly and annual) management earnings forecasts issued between 1999 and 2003 which were not preceded by any management forecasts in the 12 months prior to management earnings forecast date. ${ }^{6}$ To be included in the sample, I require forecasting firms' coverage by the CRSP, Compustat, and TAQ databases, resulting in the final sample of 1,165 initiations.

Sample selection for testing Hypothesis 4 (stopping firms only):

The sample of firms that cease issuing management earnings forecasts consists of all forecasting firms between 1999 and 2003 in the CIG database that issue

\footnotetext{
${ }^{5}$ I choose not to exclude management forecasts in the proximity to corporate events in my sample. Exclusion of such forecasts reduces sample size substantially, but does not affect my conclusions.

${ }^{6}$ The sample period begins in 1999 because this is the year when First Call CIG database begins to have significant coverage (Brown et al. (2005)), and thus it is reasonable to assume that the initiation of the forecast in the CIG database reflects the true change in the firm forecasting policy, and not the initiation of the firm coverage by CIG.
} 
at least three management earnings forecasts 12 months before the last management forecast, and issue no management earnings forecasts during the subsequent 12 months. The requirement of three management earnings forecasts prior to the last management forecast is designed to ensure that stopping firms issued regular forecasts in the past. ${ }^{7}$ This sample selection procedure results in the initial sample of 130 forecast stoppers. I also require that each stopper has CRSP and Compustat coverage at the time of the last management earnings forecast, and Market Microstructure database's coverage for the two quarters following the last forecast. This requirement results in the final sample of 116 stoppers. $^{8}$

\subsection{Information Asymmetry Measurement}

\subsubsection{Measurement periods}

\section{Testing Hypotheses 1-2.}

I measure information asymmetry for forecasting and non-forecasting firms over the same calendar periods, determined by forecasting firms' forecast dates. I measure information asymmetry measurement windows during calendar time windows to control for any macro-economic effects on information asymmetry. I measure forecasting and non-forecasting firms' information asymmetry over either short or long pre- and post-forecasting windows. The short-term pre-forecast and post forecast windows are 5, 10, or 22 trading days around management earnings

\footnotetext{
${ }^{7}$ Hutton and Stocken (2006) show that the stock market reacts more strongly management earnings forecast news when forecasting firms have a reputation for accurate and frequent forecasting.

${ }^{8}$ This sample selection procedure is consistent with Houston et al. (2006). Houston et al.'s stoppers' sample consists of 180 management earnings forecasts issued between 2002 and 2003. My sample size is smaller because of 1) differences in time period for each sample, and 2) Market Microstructure database coverage requirement.
} 
forecast dates, excluding three trading days around management earnings forecast date. The long pre-forecast and post windows are 62,125 , or 250 trading days around management earnings forecast date, excluding three trading days around management earnings forecast date. ${ }^{9}$ Figure A1 in Appendix A describes the construction of preand post-forecast windows.

\section{Testing Hypothesis 3:}

I measure information asymmetry for the initiating firms over short and long pre- and post-forecast periods similar to construction of windows for tests for Hypotheses 1-2 (Figure A2).

\section{Testing Hypothesis 4:}

Figure A3 in Appendix A describes my information asymmetry measurement methodology for stopping firms. I measure the information asymmetry of stopping firms in Periods 0,1 , and 2. Period 0 starts 65 trading days prior to the last management earnings forecast date and ends three trading days prior to the last management forecast date. Period 1 starts three trading days after the last management earnings forecast date and ends 65 trading days after the management earnings forecast date. This is the period in which the market should expect the management earnings forecast to be released. If a firm does not provide a forecast during that period, then it is reasonable to assume that informed traders realize it, and stoppers' informed trading level should begin increasing. Period 2 starts 66 trading days after last management earning forecast date and ends 125 calendar days after the

\footnotetext{
${ }^{9}$ I measure information asymmetry over progressively wider windows to be able to capture possible time-variation in information asymmetry changes. For example, a firm could experience a sudden increase in information asymmetry due to a temporary increase in informed trading. As private information becomes reflected in prices very quickly (O’Hara (1995)), this effect might only be visible over a short information asymmetry window.
} 
last management earnings forecast date. If management forecast cessation encourages informed trading, we should observe a stronger increase in informed trading in Period 2.

\subsubsection{Information Asymmetry Metrics}

I use the average daily transaction-based quoted bid-ask spreads and quoted depths, Amihud Illiquidity (Amihud (2002)), and trading volume as information asymmetry metrics (see Appendix B for definition). I use all of these liquidity measures in this test to ensure that my results are consistent across the alternative liquidity metrics proposed in the literature. Bid-ask spreads alone may not completely capture information asymmetry effects (adverse selection) because specialists and market makers could change depths without changing bid-ask spreads when reacting to information asymmetry increases (Dupont (2000)). Also, bid-ask spreads capture inventory and trading commissions' effects, both of which could confound the bidask spread adverse selection component (Callahan et al. (1997)). ${ }^{10}$ I believe that a joint analysis of all measures should reduce bias in my inferences.

I use only the Amihud (2002) Illiquidity (Iliiq) measure of firms' liquidity. Illiq is a proxy for Kyle's Lambda (Kyle (1986)) and is a negative measure of firms' liquidity (see Appendix B for definition). Illiq is estimated from CRSP data. Because Illiq is computed from daily stock returns and total daily volume, it is a

\footnotetext{
${ }^{10}$ The alternative could be to use the estimates of adverse selection components of the spread developed by Stoll (1989), or Huang and Stoll (1997) and used, for example, by Krinski and Lee (1996). However, Neal and Wheatley (1998) show that the closed end mutual funds' bid-ask spreads have an estimated adverse selection component. By definition, these funds have publicly observable portfolios and thus have no information asymmetry, suggesting that estimates of adverse selection components of the spread could be biased. Thus, I choose to focus on the total spread in conjunction with depths and Amihud Illiquidity.
} 
noisier measure than a transaction-based lambda estimated from intra-day Market Microstructure database data (e.g. Brennan and Subramanyam (1996)). Hasbrouck (2006) shows that Illiq's correlation with transaction-based lambda is $82 \%$, and with effective bid-ask spread is $93 \%$.

I also use trading volume as an additional liquidity measure since some papers (e.g. Leuz and Verrecchia (2000)) argue that greater trading volume is associated with greater liquidity. This argument assumes that trading volume is driven by uninformed liquidity trades. Kyle (1986) provides some support for this assumption in that for an informed trader to trade profitably, she has to be able to "hide" among un-informed traders, i.e. greater components of trading volume should, at least on average, be uninformed. Thus, trading volume is likely to capture greater firm liquidity. In addition, prior studies (e.g. Lee et al. (1993)) show that trading volume and bid-ask spreads are negatively correlated, and thus any observed bid-ask spread effects could actually capture changes in firm trading volume. Such observed correlations thus give another rationale for including trading volume in my analyses.

\subsection{Testing of Hypothesis 1}

Recall that Hypothesis 1 predicts that in the pre-forecast period, forecasting firms have greater information asymmetry and are less liquid than non-forecasting firms. To test Hypothesis 1, I perform univariate tests on the differences of liquidity measures in pre- and post-forecasting periods. In addition, I run the following regression for the short-window tests only.

$I A_{i, p f c}=\alpha_{0}+\alpha_{1} * M E F_{i, p f c}+\sum_{n=2}^{k} \alpha_{n} *$ Controls $_{p f c}+\sum_{n=k+1}^{k+9} \alpha_{n} *$ Year Fixed Effect ${ }_{p f c}+e_{i}$ 
where $I A$ stands for either bid-ask spreads, depths, Illiq, or volume, $M E F$ is a dummy variable equal to 1 if a firm is a forecasting firm and 0 otherwise. Control is the vector of determinants of information asymmetry metrics identified in prior literature: average daily number of transactions, average volume ${ }^{11}$, average net order flow (Stoll (2000)). ${ }^{12}$ In addition, I include other firm characteristics, measured in the end of prior quarter, to control for any differences between forecasting and non-forecasting firm samples, driven by these characteristics. Hypothesis 1 predicts that $\alpha_{1}>0$ for bidask spreads and Illiq (because Illiq is a negative liquidity measure), and $\alpha_{1}<0$ for depths and volume.

\subsection{Testing of Hypothesis 2}

Hypothesis 2 implies that management forecasting is associated with information asymmetry decreases between post- and pre-forecasting periods for forecasting firms.

These decreases are predicted to be stronger for forecasting firms than for nonforecasting firms. I thus first compare univariate changes in pre- and post-forecast period information asymmetry levels between forecasting and non-forecasting firms.

I also estimate the following regression for changes in the information asymmetry measure using short pre- and post-forecasting windows only.

$\Delta A I_{i t}=\alpha_{0}+\varphi_{1} * M E F_{i t}+\sum_{j=2}^{k} \varphi_{j}^{*} \Delta$ Control $_{i t}+\sum_{n=k+1}^{n+8} \varphi_{n}^{*}$ Year Fixed Effect $t_{t}+e_{i}$

\footnotetext{
${ }^{11}$ Volume is omitted from depth and illiquidity regressions to avoid mechanical correlations with dependent variables.

${ }^{12}$ Stoll (2000) model also includes average stock price as a bid-ask spread determinant. I omit price from information asymmetry regression because of potential endogeneity of price and bid-ask spreads. CRSP price is a mid-point of bid-ask spreads, and thus is determined from bid-ask spread itself. For the same reason, I also omit contemporaneous price volatility from this regression. Stoll (2000) argues for inclusion of price volatility in this regression to control for cross-sectional variation in stocks' risk. I include firms' historical beta to control for this effect.
} 
where $\Delta A I$ represents the average change in bid-ask spreads, Illiquidity, or depths between pre- and post-forecasting periods, and $M E F$ is a dummy variable equal to 1 if the firm is a forecasting firm and 0 otherwise. The control variables are the same as in equation 1.1. ${ }^{13}$ Hypothesis 2 predicts that $\varphi_{1}<0$ for bid-ask spreads and Illiquidity, and $\varphi_{1}>0$ for depth and volume regressions.

\subsection{Testing of Hypotheses 3 and 4}

To test Hypotheses 3 and 4, I perform univariate comparisons of long- and shortwindow information asymmetry for initiating (stopping) firms in pre- and postinitiating (stopping) periods. I estimate an equivalent of equation 2.2 for the sample of initiating (stopping) and non-forecasting (forecasting) firms only if univariate results show that forecast initiation (cessation) results in significant declines (increases) in information asymmetry.

\section{Empirical Results}

\subsection{Descriptive statistics}

Panel B of Table 1 describes the distribution of the sample's 12,207 earnings forecasts over the sample period. Consistent with Brown et al. (2005) and Johnson et al. (2002), starting in 1997, the number of management forecasts increases. ${ }^{14}$ It especially increases in 2001-2002 period, probably reflecting increases in firm

\footnotetext{
${ }^{13}$ Firm characteristics are omitted in this regression since a firm is used as its own control in equation 2.

${ }^{14}$ This change probably reflects the effect of the Private Securities Litigation Reform Act, which resulted in the greater forecast earnings forecasting frequencies (Johnson et al. (2002)).
} 
forecasting tendencies due to adoption of Regulation FD (Heflin et al. (2003), Anilowski et al. (2006)).

Panel C of Table 1 reports a breakdown of my forecasting firm sample by forecast periodicity. Quarterly forecasts represent about $57 \%$ of my sample, and annual forecasts represent $43 \%$. Panel D reports the breakdown of my sample by forecast specificity. Consistent with other studies, point and closed range forecasts represent $76 \%$ of the sample, with the remainder split between open range, confirming and qualitative forecasts. Panel D shows that almost a half of my sample is represented by multiple forecasts issued on the same forecast date. The firms' choice of forecast periodicity, precision and number of forecasts on the same day could be affected by pre-forecast liquidity level, and in turn could affect these forecasts' effects on firms' liquidity ex-post. Thus, I consider these differences in my empirical tests. Finally, Panel $\mathrm{F}$ shows industry-breakdown of forecasts in my sample. Management forecasts in my sample come from variety of different industry with no substantial industry clustering.

Table 2 presents univariate descriptive statistics for the matched sample of 12,207 forecasting and non-forecasting firms. Table 2 suggests that the forecasting and non-forecasting firms' size match is not completely effective: forecasting firms are significantly larger than the non-forecasting firms (with a median market value of equity $\$ 1,312$ million vs. $\$ 867$ million). The match is not completely effective because, to avoid reductions in my sample size, I do not impose a restriction on the size difference between forecasting and non-forecasting firms. Forecasting firms have slightly higher growth expectations (median market-to-book ratio of 2.57 vs. 
2.28 ) and higher leverage (median debt-to-assets ratio of 0.53 vs. 0.49 ). In addition, forecasting firms have lower volatility of unexpected earnings (mean 0.017 vs. 0.02 ), higher institutional ownership (median $64 \%$ vs. 56\%), and higher analyst following (median of 9 vs. 6). Overall, these results suggest that forecasting firms have more sophisticated information environment and support my conjecture, underlying Hypothesis 1, that forecasting firms should also be more liquid. However, significant differences in firm characteristics in two samples suggest that any observed differences in firms' liquidity simply reflect differences in firm characteristics, and not necessarily in their forecasting status. Thus, I control for firm characteristics in my multivariate tests.

\subsection{Results of Tests of Hypotheses 1 and 2}

\subsubsection{Short forecasting window tests}

Table 2.3, Panel A summarizes univariate comparisons of median quoted bid-ask spreads, depths, Illiq, and trading volume of 12,207 forecasting and non-forecasting firms in the pre- and post-forecasting periods. I report results for five, ten, and 22trading day windows around management earnings forecast date. These windows exclude 3 trading days immediately around management earnings forecast date. ${ }^{15} \mathrm{I}$ report results for these three progressively wider windows to capture any effects in short-term pre-forecast information asymmetry increases which could occur over different times during pre-forecast periods. Forecasting firms' median pre-forecasting

\footnotetext{
${ }^{15}$ Information asymmetry is likely to increase, and Liquidity is to decrease right after a management forecast announcement because market makers want to protect themselves against likely informed trading right around an announcement time (Kim and Verrecchia (1994)). I am excluding this period since the research questions of this paper are focused not on short-term predictable announcement liquidity changes, but on longer-term pre- and post-announcement effects of management forecasts.
} 
period bid-ask spreads are lower, quoted depths are higher, Illiq is lower, and trading volume is higher than those of non-forecasting firms across all trading windows. The median quoted pre-forecasting period half-spread for forecasting firms is $\$ 0.04$ vs. $\$ 0.05$ for non-forecasting firms (five-day window), with differences significant at 0.01 level. Magnitudes of half-spreads for forecasting and non-forecasting firms for ten and 22 trading day windows are similar to those of five day window. The median five day window pre-forecasting period depth for forecasting firms is 2,250 shares per transaction vs. 1,987 shares per transaction for non-forecasting firms. The median five day window pre-forecasting period Illiq of forecasting firms is 0.05 vs. 0.12 for non-forecasting firms ${ }^{16}$, and median five day window pre-forecasting period turnover of forecasting firms is 4.83 vs.3.76 for non-forecasting firms. The latter results are consistent with those for ten and 22 trading day windows. Overall, these results suggest that forecasting firms are more liquid than non-forecasting firms in preforecast period.

Post-forecasting period liquidity patterns are similar. Median five-day window forecasting firms' bid-ask spreads and Illiq are lower than those of nonforecasting firms ( 0.04 vs. 0.05 , and Illiq of 0.04 vs. 0.11$)$. Median forecasting firms' depths for five-day window are higher than non-forecasting firms' depths at 2,346 shares per transaction vs. 1,996 shares per transaction. Similarly, forecasting firms' median daily turnover is 5.8 vs. 3.85 for non-forecasting firms. Results for ten and 22 trading day-windows are similar.

Thus, we could see that forecasting firms become slightly more liquid in the post-forecasting period, but all liquidity metrics of non-forecasting firms remain un-

\footnotetext{
${ }^{16} \mathrm{Illiq}$ is a negative liquidity measure.
} 
changed. The results in Panel B of Table 3 support this observation. For five day window, forecasting firms experience a median decline in half-spreads of $-4 \%$, while non-forecasting firms' spreads change is only $-1 \%$. Similarly, for five day window, forecasting firms' depths experience a median increase of 3\% vs. $0 \%$ median change for non-forecasting firms. Five day window forecasting firms' Illiq has a median change of $-15 \%$ vs. $-2 \%$ change for non-forecasting firms. Similarly, in five day window, turnover shows a median increase of $13 \%$ for forecasting firms, and does not change for non-forecasting firms. Importantly, magnitudes of these changes for ten day and 22 day window are similar to those of five day window test results for quoted half-spreads, but are a little smaller for other liquidity metrics. In general, results suggest that forecasting results in short-term improvements in liquidity.

I report the results of OLS estimations of equation 1 in Panel A of Table 4. Regression models are estimated using year fixed effects and standard errors clustered at firm level, as suggested by Petersen (2006). Because regression results using other windows are similar, I report only 22-day window regression results. In all four regressions, quoted bid-ask spreads, quoted depths ${ }^{17}$, illiquidity and volume, MEF variable is not significant. That is, controlling for liquidity determinants, preforecast liquidities of forecasting and non-forecasting firms are not significantly different from each other. These results thus suggest that differences in pre-forecast liquidity of forecasting and non-forecasting firms, observed in Table 3 are driven entirely by underlying firm characteristics, and controlling for those characteristics,

\footnotetext{
${ }^{17}$ A number of papers (e.g. Heflin et al. (2006) argue that since quoted depths and spreads are negatively correlated, depths should be included in spreads regression as an explanatory variable, and vice versa. I do so in un-tabulated regressions, and the results are unchanged.
} 
liquidity of forecasting and non-forecasting firms is not different, failing to reject Hypothesis 1.

Panel B of Table 4 summarizes OLS estimations of Equation 2. In the bid-ask spreads' changes regression, the MEF coefficient is negative, and significant, suggesting that, upon management earnings forecast issuance forecasting firms experience greater decreases in bid-ask spreads than non-forecasting firms. In the depths' changes regression, the results are consistent with those of bid-ask spreads' changes regression: coefficient on MEF is positive and significant, suggesting that earnings forecasting increases depths. ${ }^{18}$ Similar significant results are obtained in Amihud Illiquidity. However, I observe no significant difference in turnover changes between forecasting and non-forecasting firms. Taken as a whole, evidence suggests that earnings forecasting improves liquidity. ${ }^{19}$

\subsubsection{Long forecasting window tests}

Panel A of Table 5 presents the analyses of differences in liquidity for forecasting and non-forecasting firms using long forecasting windows of 62,125 , and 250 trading days around management earnings forecast date (excluding three trading days around the announcement date). Consistent with short-window tests, the results in this panel

\footnotetext{
${ }^{18}$ Some studies suggest controlling for correlation between spreads and depths in these regressions. I re-run my tests with these controls, and results remain qualitatively unchanged.

${ }^{19}$ Simultaneity is a potentially difficult econometric issue in these regressions. Since a market maker could use both depths and spreads to respond information asymmetry levels, these two variables are endogenous to each other. In addition, volume is influenced by bid-ask spread levels (Kim and Verrecchia (2003)). These observations suggest that it is possible that, in equilibrium, liquidity metrics are simultaneously determined. I thus run use a simultaneous equations framework, using firm characteristics from equation 2.1, as instruments. Generally, the results remain consistent with those reported by OLS. The difference is that in simultaneous equations framework, I find no significant differences in changes in bid-ask spreads of forecasting and non-forecasting firms over 22 trading day window. I still find a significant result with respect to depths and illiquidity. Thus, simultaneous equations estimation generally supports OLS.
} 
suggest that forecasting firms are more liquid in the pre-forecast period than nonforecasting firms. Across all windows, forecasting firms' bid-ask spread and Illiquidity are lower, and depths and volume are higher than those of non-forecasting firms. Similarly, forecasting firms are more liquid in the post-forecasting period. Thus, these results contradict Hypothesis 1.

Panel B of Table 5 summarizes comparisons of long-term changes in liquidity of forecasting and non-forecasting firms upon management earnings forecast issuance. Bid-ask spreads of forecasting firms decrease to greater extent than those of non-forecasting firms in all three windows. It is interesting to note that depths decline for both forecasting and non-forecasting firms over long windows, albeit a decline is smaller for forecasting firms in 62 and 125 trading days windows. No significant differences in changes of Illiquidity and volume are observed for any of these windows. Hence, evidence of long-term management forecast liquidity effect is weak. ${ }^{20}$

Similar to Table 4, Table 6 summarizes multivariate tests of Hypotheses 1 and 2 for 125 trading day window (results for other long windows are consistent). Consistent with results in Table 4, Panel A of Table 6 shows that, controlling for firm characteristics and liquidity determinants, no differences in pre-forecast liquidity is observed between forecasting and non-forecasting firms. Thus, Hypothesis 1 is rejected. With respect to liquidity changes around management earnings forecast date, Panel B of Table 6 shows that bid-ask spreads decrease to greater extent for forecasting firms than non-forecasting firms. Furthermore, it is accompanied by a

\footnotetext{
${ }^{20}$ As a robustness test, I also use simultaneous equations estimation here as well. The results are consistent with OLS,
} 
decline in share turnover for forecasting firms. These results thus provide no strong support for Hypothesis 2.

Summary: The evidence in Tables 3-6 suggests that forecasting firms are more liquid than non-forecasting firms before management earnings forecasts are issued, contradicting Hypothesis 1. The results also show that management forecasts provide some short-term liquidity improvement. Long forecasting window tests fail to find persistent increases in forecasting firms' liquidity. Thus, Hypothesis 2 is rejected. Figures 1-3 illustrate these findings. Figure 1 shows the average quoted half-spread for forecasting and non-forecasting firms in my sample over 250 trading days before and after the management forecast date. Note that forecasting firms' quoted halfspread graph is always strictly below that of non-forecasting firms'. Half-spreads of both forecasting and non-forecasting firms initially stay the same, then simultaneously increase, and then jointly decline over time. Forecasting firms experience a temporary increase in half spread right after management earnings forecasts are issued; however, no greater downward shift in quoted half-spread is observed for forecasting firms (perhaps a very small shift is visible, but hardly a material one).$^{21}$ Similarly, Figure 2 does not show any significant changes in firm depths right after management earnings forecast date. It is interesting to note that both bid-ask spreads and depths graphs very similar liquidity behavior of forecasting and non-forecasting firms over time. In particular, both types of firms experience a run-up in spreads and depths prior to management forecast date. Furthermore, about 156 trading days after management forecast date, depths of non-forecasting firms decline.

\footnotetext{
${ }^{21}$ A potentially interesting result in Figure 2.1 is common downward trend pattern in bid-ask spreads of forecasting and non-forecasting firms. Perhaps this trend reflects common liquidity time-series liquidity patterns in the same industry. I leave explanation of this result for future research.
} 
Similarly, spreads of non-forecasting firms experience a slight increase around the same time. This pattern provides some support for an argument that perhaps forecasts are issued to prevent future declines in liquidity. However, it is difficult to draw such conclusions since an observed decline in depths and increase in spreads of the nonforecasting firms occurs almost 7 months after the management forecast date.

Similar liquidity patterns in results shown in Figure 3 show a slight decline in forecasting firms' Illiquidity right around management earnings forecast date, and Illiquidity quickly returns to pre-forecast level. Similarly to spreads and depths, nonforecasting firms' Illiquidity increases around 142 trading days after management earnings forecast date. Similarly, share turnover of forecasting firms does not also show any persistent upward changes. Forecasting firms experience a strong "spike" in turnover right around management earnings forecast date, but this increase does not persist. Thus, graphic evidence does not support a prediction of Hypothesis 2.

\subsubsection{Additional Analyses}

\section{Cross-sectional variation in liquidity effects of different forecast types}

As Panels B-E of Table 1 indicate management earnings forecasts in my sample vary in terms of 1) periodicity (i.e. quarterly vs. annual forecasts) and horizon (i.e. distance from the forecast date to the end of the period for which earnings are forecast), 2) specificity (i.e. whether a forecast is point, closed range, confirming, open range, or qualitative), and 3) in terms of number of forecasts issued on the same forecast date. Pre-forecast liquidity level could have an effect on a decision when and which type of forecast is issued. For example, annual forecasts could be more 
informative because they cover the entire year, and not just a quarter, but they also could be less informative because annual forecasts tend to be issued earlier in the year, and thus are subject to greater forecast error. Alternatively, a point and closed range forecasts could be perceived by market makers as being more informative, and thus could lead to greater reductions of bid-ask spreads. The question of how different forecast characteristics are correlated with pre-forecast liquidity levels, and the postforecast liquidity effects is beyond the scope of this study. However, I re-perform all univariate analyses of pre-forecast liquidity and forecasts' liquidity effects to ensure that my conclusions are generalizable to all types of forecasts. I do not find results for any forecast class that substantially changes conclusions of tests reported in Tables 36. These analyses are un-tabulated for brevity.

\subsection{Results of Tests of Hypothesis 3}

Panel A of Table 7 examines the effects of management forecast initiation on forecasting firms' liquidity for 22 trading day window and 125 trading day window (other windows' results are consistent with those reported). For comparison, I also report pre-forecast liquidity levels of initiating firms and control non-forecasting firms. Consistent with the overall forecasting firms' sample examined previously, initiating firms are more liquid than non-forecasting firms. Forecast initiation has short-term benefits: all liquidity measures improve in 22 trading day window. In particular, bid-ask spreads decrease by $6 \%$ vs. $2 \%$ for non-forecasting firms, depths

increase by $3 \%$ vs. decrease of $1 \%$ for non-forecasting firms, illiquidity decreases by $10 \%$ vs. $5 \%$ for non-forecasting firms, and volume increases by $9 \%$ vs. $1 \%$ for non- 
forecasting firms. However, no significant changes in liquidity occur in 125 trading day window, suggesting that benefits of forecast initiation are not long-term. Figures 5A-5C confirm this conclusion. No persistent changes are observable for either bidask spreads, depths, Illiquidity, or volume. In general, forecast initiation appears to have the same effects as regular forecasting. This observation is supported by the empirical results in Panel B of Table 7. For 22-trading day window, bid-ask spreads changes, depths, and Illiq regressions shows that, upon forecast initiation, initiating firms have more significant changes in liquidity than non-forecasting firms (significant coefficients on MEF variable of $-0.03,0.07$, and -0.08 respectively). Changes in share turnover between initiating and non-forecasting firms are not significantly different from each other. However, except bid-ask spreads, MEF variable is not significant in other regressions for 125 trading day window, suggesting that forecast initiation has no strong liquidity benefits.

One potential concern in my tests is that my results could be confounded by the effects of earnings announcements that occur either concurrently with management forecasts or in close proximity to management earnings forecast date. To consider these potentially confounding effects, I split my initiation sample into two groups: management forecasts made within five calendar days of the end of the fiscal period, and those made more than five days before. I find that almost $2 / 3$ of initiations in my sample take place within five days of the end of the fiscal period, and thus potential confounding effects if earnings announcements need to be taken into account. My un-tabulated analyses reveal some differences from results reported in Panel B of Table 6. In particular, I observe no significant declines in bid-ask spreads 
or increases in volume upon management forecast initiation in either forecasts issued more than 5 days before the end of the period, or forecasts issued within five day period. With respect to depths, the observed increase in depths over 22 day period is driven by forecasts issued more than five days after management earnings forecast date. Similarly, decline in Illiquidity observed over 22 trading day window is driven by forecasts issued more than five days before the end of their fiscal periods. Finally, no significant changes in liquidity across all measures is observed over 125 trading day windows for either forecasts issued more than 5 days before the end of the fiscal period, or issued within five days before the end of the fiscal period. Overall, the results in Table 6 do not provide strong support for the contention that management earnings forecast initiation yield information asymmetry reduction benefits and, therefore, generally reject Hypothesis 3 .

Forecast initiation effect on initiating firms' information asymmetry could become stronger as initiating firms establish a reputation for regular earnings forecasting. Such a reputation is an evidence of implied commitment to future disclosure. Consistent with this conjecture, Hutton and Stocken (2006) show that stock market reacts stronger to management earnings forecast news of forecasting firms with reputation for frequent and accurate forecasting. I therefore select a subsample of forecast initiators that issue their second forecast within 180 days after the first forecast, and issue at least four forecasts between 1999 and 2003. I also require that a forecasting firm in this sample have at least two management earnings forecasts subsequent to the initiating management earnings forecast. This restriction ensures that I do not pick up firms that only sporadically forecast earnings. This sample 
selection procedure results in the sub-sample of 521 initiations. I then compare these firms' liquidity levels measured over 30 trading days after the second and third management earnings forecasts to liquidity levels measured over the 20 trading days immediately after forecast initiation. Un-tabulated results show that bid-ask spreads decline after both the first and second management forecasts. However, for the same period, I find a small, yet statistically significant decline in depths, and no changes in either Illiq or volume. Thus, these results suggest that even when a firm establishes a subsequent forecasting reputation, management earnings forecast initiation does not result in unambiguous improvement in liquidity.

\subsection{Results of Tests of Hypothesis 4}

Table 8 summarizes the analyses of changes in information asymmetry for stopping firms. Comparing Period 0 liquidity to that of Period 1, it is apparent that liquidity levels remain unchanged for all information asymmetry metrics, suggesting that management forecast cessation does not strongly affect firms' liquidity and information asymmetry. Un-tabulated comparisons of stoppers' information asymmetry metrics in Period 0 and Period 2 produce similar results (see Figures 6A$6 \mathrm{D})^{22}$.

\section{Conclusion}

In their Expectation Adjustment Hypothesis, Ajinkya and Gift (1984) and King et al. (1991) suggest that firms issue management earnings forecasts to reduce costly

\footnotetext{
${ }^{22}$ It could be seen from these graphs that in about 140 trading days, liquidity of stopping firms changes: bid-ask spreads, Illiquidity, depths and volume all increase. However, due to long passage of time since the last forecast date, it is hard to directly attribute these changes to cessation of the forecasting policy.
} 
information asymmetries between informed and un-informed investors and improve firms' current liquidity. Coller and Yohn (1997) provide evidence supporting this conjecture. However, recent studies suggest that forecasting firms are already more liquid and have high quality disclosure policies in place. These findings call into question 1) whether earnings forecasting is aimed to improve forecasting firms' current liquidity and 2) whether management earnings forecasts have a persistent effect on forecasting firms' liquidity.

This paper examines questions (1) and (2) using the expanded 1994-2003 management earnings forecast sample. The results suggest that 1) forecasting firms are more liquid in the pre-forecast period, and 2) the liquidity effect of management earnings forecasts is very short-term. The results do not support the existence of strong liquidity effects as the result of initiating management forecasting policy or for a cessation of management earnings forecasting policy.

Future research could investigate the relation between management's policies for forecasting earnings and firms' cost of capital. The focus of this study is on the management earnings forecasts' relation to liquidity, but Verrecchia (2001) argues for linking disclosure, liquidity, and the cost of capital. It would be interesting to know how levels of the management earnings forecast disclosure and other firm's disclosures (e.g. annual reports, earnings announcements, and conference calls) jointly affect liquidity and the cost of capital. Also, future papers could explore the factors that strengthen the liquidity effect of management's earnings forecasts, such as the value relevance of earnings or variation in the number of signals disclosed in the press releases for management's earnings forecasts. 


\section{Appendix A: Information Asymmetry Measurement Windows:}

Figure A1: Liquidity measurement windows (general case):

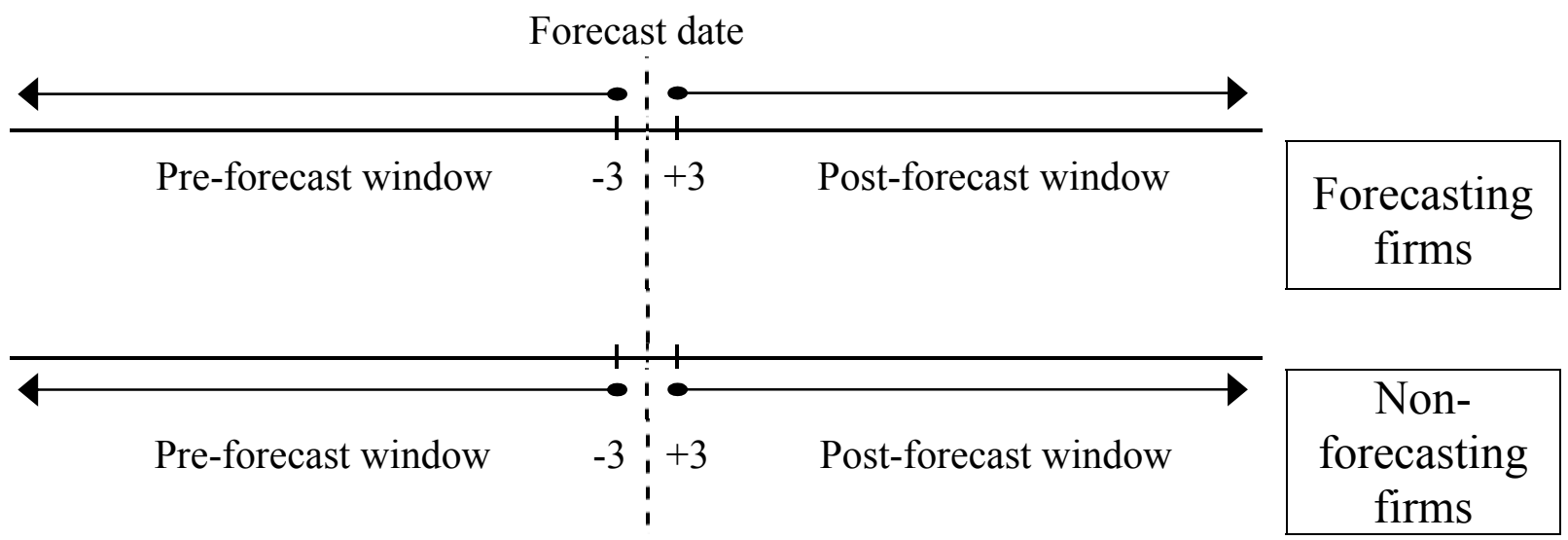

Figure A2: Forecast Initiation Windows

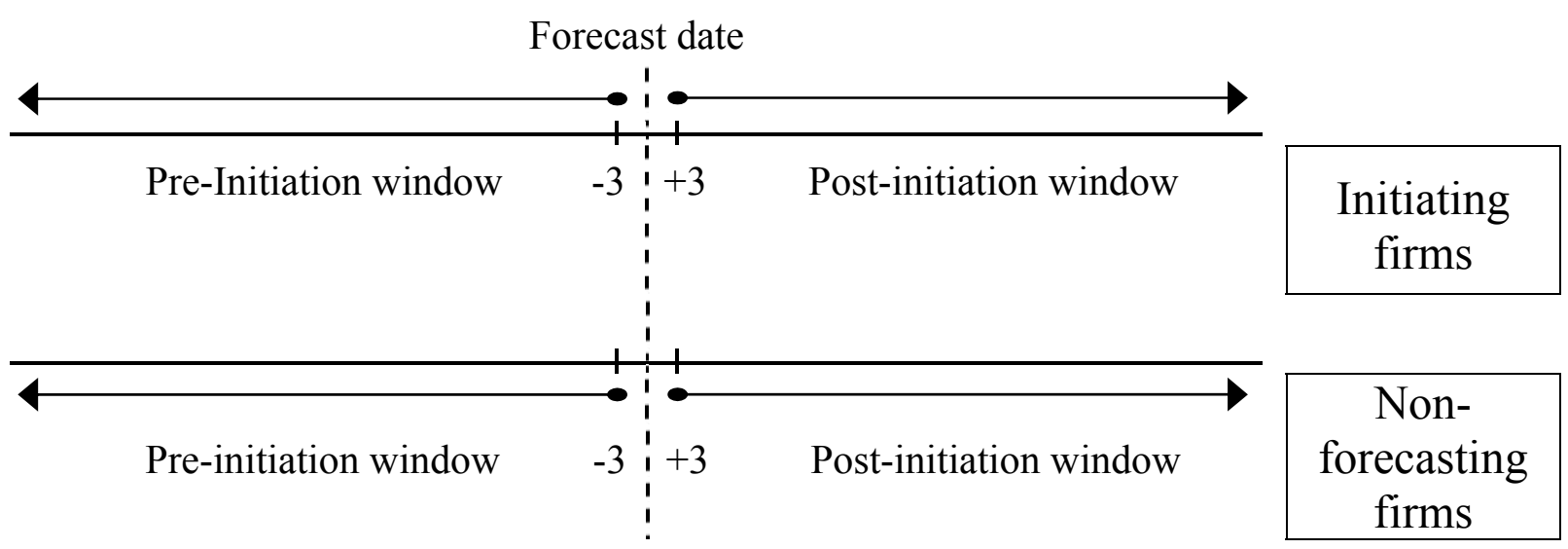

Figure A3: Forecast Cessation Windows

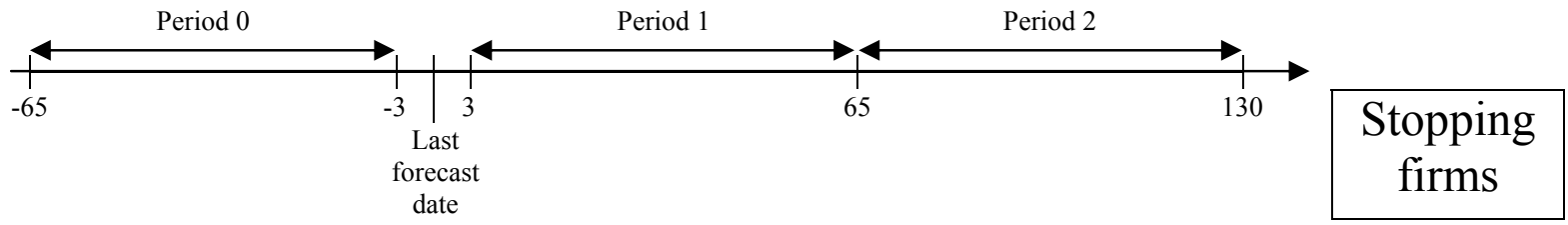




\section{Appendix B}

\section{Variable Definitions}

\section{Information Asymmetry (Liquidity) Metrics}

Amihud Illiquidity (Illiq)

Quoted Half Spreads

Quoted Depths

\section{Independent and control variables}

$M E F$

Prior spread

Prior depth

Prior volume

Trades

Volume

NOF

$M V E_{t-1}$
Illiq $_{i t}=\frac{1}{N} \sum_{i=1}^{N} \frac{\left|\operatorname{Re} t_{i t}\right|}{V o l_{i t}} * 10^{6}$

where $N$ represents the number of days in the estimation period, Ret is the daily stock return, and $\mathrm{Vol}$ is the total number of shares traded during the day.

One half of absolute difference between best bid and ask price

Sum of shares quoted on both bid and ask sides of the market maker's quote, weighted by trade size.

A dummy variable that equals 1 if a firm is a forecasting firm, and 0 otherwise.

Average quoted half-spread over the year ending 360 days before management forecast date. Obtained from Market Microstructure Database.

Average quoted depth, weighted by trade size, over the year ending 360 days before management forecast date. Obtained from Market Microstructure database.

Average trading volume, over the year ending 360 days before management forecast date. Obtained from Market Microstructure database.

Average daily number of all transactions during at the pre-forecasting period.

Natural $\log$ of the average daily CRSP volume during the pre-forecasting period volume

Absolute value of difference between number of buys and sells during the trading day Market Value of Equity in the prior 
$M T B_{t-1}$

$R O A_{t-1}$

Leverage $_{t-1}$

Age

Beta

Uearn_Vol

Perc_Inst

Anal_fol

Sharinst_net

Litigate

$F D$

Event quarter (in descriptive statistics).

Firm's market-to-book ratio in the prior quarter

Firm's return on assets in the prior quarter

Firms' debt-to-total assets in the prior quarter

Number of years since a firm was reported in CRSP for the first time Market Beta from three factor model estimated over 36 quarters

Standard deviation of unexpected earnings estimated over 12 quarters. Unexpected earnings is defined as a residual from regression of earnings in quarter on earnings in the same quarter a year ago (random walk model).

Percentage institutional ownership obtained from CDA Spectrum

Number of individual analysts issuing forecasts during quarter $t-1$. Obtained from IBES

Different between shares purchased by insiders and shares sold by insiders. Obtained from CDA Spectrum.

A dummy variable equal 1 if a firm falls into "high litigation risk" industry per Francis et al. (1994)

A dummy variable equal 1 if management forecast is issued after October 2000.

A Dummy variable that equals 1 if there was a corporate event within 30 days of the management earnings forecast date. A corporate event is a merger, acquisition, restructuring, or stock issuance. 


\section{References:}

Ajinkya, B. and M. Gift (1984). Corporate managers' earnings forecasts and market expectations. Journal of Accounting Research, 22(2), 425-444.

Ajinkya, B., S. Bhojraj, and P. Sengupta (2005). The association between outside directors, institutional investors, and the properties of management earnings forecasts. Journal of Accounting Research, 43(3), 343-376

Amihud, Y. (2002). Illiquidity and stock Returns: cross-section and time-series effects. Journal of Financial Markets, 5, 31-56

Anilowski, C., M. Feng, and D. Skinner (2006). Does earnings guidance affect market returns? The nature and information content of aggregate earnings guidance. Forthcoming in Journal of Accounting and Economics.

Baginski, S. and J. Hassel (1990). The market interpretation of management earnings forecasts as a predictor of subsequent analyst forecast revisions. The Accounting Review 65(1), 175-190.

Baginski, S., J. Hassel and M. Kimborough (2002). The effect of legal environment on voluntary disclosure: evidence from management earnings forecasts issued in U.S. and Canadian Markets. The Accounting Review, 77(1), 25-50

Brennan, M. and Subrahmanyam, A. (1995). Investment analysis and price formation in securities markets. Journal of Financial Economics, vol. 38, pp. 361-381.

Brown, S., S. Hillegeist, and K. Lo (2003). Conference calls and information asymmetry. Journal of Accounting and Economics, 37, 343-366.

Brown, S., S. Hillegeist, and K. Lo (2005). Management forecasts and litigation risk. Working paper. Emory University.

Bushee, B. and T. Goodman (2007). Which institutional investors trade based on private information about earnings and returns? Journal of Accounting Research, 45(2), 289-332

Callahan, C., C. Lee and T. Yohn (1997). Accounting information and bid-ask spreads. Accounting Horizons, 11(4), 50-60

Chen, S., D.Matsumoto, S. Rajgopal (2005). Is silence golden? An empirical analysis of firms that stop giving quarterly earnings guidance in the post RegulationFD period. Working Paper. University of Washington.

Clement, M., R. Frankel, and J. Miller (2003). Confirming management forecasts, 
earnings uncertainty and stock returns. Journal of Accounting Research, 41(4), 653-680

Coller, M. and T. Yohn (1997). Management forecasts and information asymmetry: an examination of bid-ask spreads. Journal of Accounting Research, 35(2), 181-191

Copeland, T. and D. Galai (1983). Information effects and bid-ask spread. Journal of Finance, 38, 1457-1469

Cotter, J., I. Tuna, P. Wysocki, and J. Callen (2006). Expectations management and beatable targets: how do analysts react to public earnings guidance? Contemporary Accounting Research, 23(3), 592-628

Dupont, D. (2000). Market making, prices and quantity limits. Review of Financial Studies, 13(4), 1129-1151

Easley, D., N. Kiefer and M. O'Hara (1997). One day in life of a very common stock. The Review of Financial Studies, 10(3), 805-835

Easley, D., S. Hvidkjaer, and M. O'Hara (2002). Is information risk a determinant of asset returns? Journal of Finance, 57(5), 2185-22221

Frankel, R. M. McNichols, and P. Wilson (1995). Discretionary disclosure and external financing. The Accounting Review, 70(1), 135-150

Francis, J., D. Nanda and P. Olsson (2005). Voluntary disclosure, information quality, and the cost of capital. Working paper. Duke University

Field, L., M. Lowry and S. Shu (2005). Does disclosure deter or trigger litigation? Journal of Accounting and Economics, 39(3) 487-507

Glosten, L. and P. Milgrom (1985). Bid, ask, and transaction prices in a specialist Market with heterogeneously informed traders. Journal of Financial Economics, 13, 71-100.

Graham, J., C. Harvey and S. Rajgopal (2005). The economic implications of Corporate financial reporting. Journal of Accounting and Economics, 40, 3-73

Harris, L. (2003). Trading and Exchanges. Oxford University Press.

Hasbrouck, J. (2006). Trading costs and returns for the U.S. equities: estimating effective costs from the daily data. Working Paper. New York University

Healy, P. and C. Palepu (2001). Information asymmetry, corporate disclosure and capital markets. Journal of Accounting and Economics, 31, 405-440 
Heflin, F., K. R. Subramanyam, and Y. Zhang (2003). Regulation FD and the Financial Information Environment: Early Evidence. The Accounting Review, Vol. 78, No. 1, January 2003, pp. 1-37.

Heflin, F., K. Shaw and J. Wild (2005). Disclosure quality and market liquidity: the effect of depth quotes and order sizes. Contemporary Accounting Research, 22(4), 829-865.

Houston, J., B. Lev and J. Tucker (2005). To guide or not to guide? Causes and consequences of stopping and subsequently resuming earnings guidance. Working Paper. University of Florida.

Hutton, A., P. Healy and K. Palepu (1999). Stock performance and intermediation changes surrounding sustained increases in disclosure. Contemporary Accounting Research, 16(3), 485-520

Hutton, A. and P. Stocken (2006). The effects of reputation on credibility of management forecasts. Working Paper. Dartmouth College.

Johnson, M., R. Kasznik, and K. Nelson (2001). The effect of securities litigation reform on the disclosure of forward-looking information by high technology firms. Journal of Accounting Research, 39(2), 297-328

Kim, O. and R. Verrecchia (1994). Market liquidity and volume around earnings announcements. Journal of Accounting and Economics, 17, 41-67

King, R., G. Pownall, and G. Waymire (1990). Expectations adjustment via timely earnings forecast disclosure: review, synthesis, and suggestions for future research. Journal of Accounting Literature, 9, 113-144.

Krinski, Y. and J. Lee (1996). Earnings announcements and components of the bid-Ask Spreads. Journal of Finance, September 1996, 1523-1535

Kyle, A. (1985). Continuous auctions and insider trading. Econometrica, 53, 13151336

Lang, M. and R. Lundholm (1996). Corporate disclosure policies and analyst behavior. The Accounting Review, 71(4), 467-492

Lang, M. and R. Lundholm (2000). Voluntary disclosure and equity offerings: reducing information asymmetry or hyping the stock? Contemporary Accounting Research, 17(4), 623-662

Lee, C. and M. Ready (1991). Inferring trade direction from intra-day data. Journal of Finance, 46(2), 733-746 
Lee, C., B. Mucklow and M. Ready (1993). Spreads, depths, and the effect of earning information: an intraday analysis. The Review of Financial Studies, 6, 345-374

Leuz, C. and R. Verrecchia (2000). The economic consequences of increased disclosure. Journal of Accounting Research, 38, Supplement, 91-124

Marquardt, C. and C. Wiedman (1998). Voluntary disclosure, information asymmetry, and insider selling through secondary equity offerings. Contemporary Accounting Research, 15(4), 505-538

McNichols, M. and B. Trueman (1994). Public disclosure, private information collection, and short-term trading. Journal of Accounting and Economics, $\underline{17(1)}$

Miller, G. (2003). Earnings performance and discretionary disclosure. Journal of Accounting Research 40(1), 173-204

Myers, S., and N. Majluf (1984). Corporate investment and financing decisions when firms have information that investors do not have. Journal of Financial Economics:13 (2), 187-221

Neal, R. and S. M. Wheatley (1998). Adverse selection and bid-ask spreads: Evidence from closed-end funds. Journal of Financial Markets 1, 121-149.

Noe, C. (1999). Voluntary disclosures and insider transactions. Journal of Accounting and Economics, 27(3), 305-326

Petersen (2005). Estimating standard errors in finance panel data sets: comparing approaches. Working Paper. Northwestern University.

Rock, K. (1986). Why new issues are under-priced? Journal of Financial Economics, $15,187-212$

Schrand, K., and R. Verrecchia (2005). Information disclosure and adverse selection explanations for IPO underpricing. Working Paper. University of Pennsylvania.

Skinner, D. (1994). Why firms voluntarily disclose bad news. Journal of Accounting Research, 32(1), 38-72

Soffer, L., R. Thiagarajan, and B. Walther (2000). Earnings pre-announcement strategies. Review of Accounting Studies, 5, 5-26 
Stocken, P. (2000). Credibility of voluntary disclosure. Rand Journal of Economics, 31(2), 359-374

Trueman, B. (1986). Why do managers voluntarily release management forecasts? Journal of Accounting and Economics, 8(1), 53-71

Stoll, H. (2000). Friction. Journal of Finance, 55(4), 1479-1516

Verrecchia, R. (2001). Essays on disclosure. Journal of Accounting and Economics, 32, 97-180

Welker, M. (1995). Disclosure Policy, information asymmetry and liquidity in equity markets. Contemporary Accounting Research, Spring 1995, 805-827

Yan, Y. and S. Zhang (2006). An improved estimation method and empirical properties of PIN. Working Paper. WRDS at University of Pennsylvania and Nyang Technological University. 
Panel A:

\section{Sample Selection Procedure}

Sample Selection Criteria

Number of Earnings Forecasts of US firms in First Call

between 1994 and 2003

Coverage by MM Database*

Availability of prior quarter and current quarter earnings announcement date in Compustat

Availability of size matches on Compustat

Include only forecasts with 2 years of data in MM database to compute necessary liquidity measures for both forecasting and non-forecasting firms and having Compustat variables non-missing **

\section{\# of observations}

*MM (Market Microstructure) Database is provided courtesy of Financial Markets Research Center in Owen School of Business at Vanderbilt University

** See Appendix A for variable definitions 


\section{Table 1: Forecasting Sample Composition}

Panel B: Forecasting Sample Composition by Year

\begin{tabular}{cc}
$\begin{array}{c}\text { Forecast } \\
\text { Year }\end{array}$ & $\begin{array}{c}\text { Number of } \\
\text { Management } \\
\text { Forecasts in the } \\
\text { Sample }^{\mathbf{1}}\end{array}$ \\
\hline 1994 & 5 \\
1995 & 184 \\
1996 & 320 \\
1997 & 561 \\
1998 & 1,208 \\
1999 & 992 \\
2000 & 943 \\
2001 & 2,516 \\
2002 & 4,306 \\
2003 & 1,172 \\
\hline Total & $\mathbf{1 2 , 2 0 7}$
\end{tabular}

Panel C: Forecasting Sample Composition by Forecast Periodicity

\begin{tabular}{|c|c|}
\hline $\begin{array}{c}\text { Forecast } \\
\text { Periodicity }\end{array}$ & $\begin{array}{c}\text { Number of } \\
\text { Management } \\
\text { Forecasts in the } \\
\text { Sample }^{1}\end{array}$ \\
\hline Quarterly & 7,025 \\
\hline Annual & 5,182 \\
\hline
\end{tabular}

Panel D: Forecasting Sample Composition by Forecast Precision

\begin{tabular}{cc}
$\begin{array}{c}\text { Forecast } \\
\text { Precision } \\
\text { Level }\end{array}$ & $\begin{array}{c}\text { Number of } \\
\text { Management } \\
\text { Forecasts in the }^{\text {Sample }^{1}}\end{array}$ \\
\hline Point & 2,509 \\
Closed Range & 6,728 \\
Open Range & 817 \\
Confirming & 1,179 \\
Qualitative & 974 \\
\hline & $\mathbf{1 2 , 2 0 7}$
\end{tabular}


Panel E: Forecasting Sample Composition by Multiple Forecasts Issued on the Same Forecast Day

\begin{tabular}{cc}
$\begin{array}{c}\text { Forecast } \\
\text { Periodicity }\end{array}$ & $\begin{array}{c}\text { Number of } \\
\text { Management } \\
\text { Forecasts in the }^{\text {Sample }}\end{array}$ \\
\hline Single Forecasts & 6,222 \\
Multiple Forecasts & 5,985 \\
\hline & $\mathbf{1 2 , 2 0 7}$
\end{tabular}

Panel F: Forecasting Sample Composition by Industry

\begin{tabular}{|c|c|c|c|}
\hline $\begin{array}{c}\text { 2-digit } \\
\text { SIC code }\end{array}$ & $\begin{array}{l}\text { Number of } \\
\text { Management } \\
\text { Earnings } \\
\text { Forecasts in the } \\
\text { Sample }^{1}\end{array}$ & $\begin{array}{c}\text { 2-digit } \\
\text { SIC code }\end{array}$ & $\begin{array}{l}\text { Number of } \\
\text { Management } \\
\text { Earnings } \\
\text { Forecasts in the } \\
\text { Sample }^{1}\end{array}$ \\
\hline $10-19$ & 337 & 59 & 302 \\
\hline 20 & 350 & 60 & 369 \\
\hline $21-25$ & 382 & $61-67$ & 615 \\
\hline $26-27$ & 400 & $70-72$ & 64 \\
\hline 28 & 1,078 & 73 & 1,251 \\
\hline $29-33$ & 344 & $75-99$ & 546 \\
\hline 34 & 201 & & \\
\hline 35 & 983 & & \\
\hline 36 & 984 & & \\
\hline 37 & 400 & & 12,207 \\
\hline 38 & 885 & & \\
\hline $39-48$ & 412 & & \\
\hline 49 & 533 & & \\
\hline $50-52$ & 378 & & \\
\hline $53-55$ & 319 & & \\
\hline 56 & 577 & & \\
\hline $57-58$ & 497 & & \\
\hline
\end{tabular}

${ }^{1}$-See Panel A of Table 1. for Sample Selection Criteria 


\section{Table 2: Descriptive statistics}

The table reports univariate descriptive statistics for the matched sample of forecasting and nonforecasting firms for which necessary CRSP and Compustat data are available. It compares the characteristics of the population of the quarterly management earnings forecasts with no confounding corporate events to the population of all non-forecasting firms in the same time period. $t$ is the calendar quarter between 1994-2003.

\begin{tabular}{|c|c|c|c|c|c|c|}
\hline \multirow[b]{2}{*}{ Variable } & \multicolumn{2}{|c|}{$\begin{array}{c}\text { Forecasting Firms; } \\
\mathrm{N}=\mathbf{1 2 , 2 0 7}\end{array}$} & \multicolumn{2}{|c|}{$\begin{array}{l}\text { Non-Forecasting } \\
\text { Firms; N=12,207 }\end{array}$} & \multirow[b]{2}{*}{$\begin{array}{c}\text { t-statistic } \\
\text { of } \\
\text { difference } \\
\text { in means } \\
\end{array}$} & \multirow[b]{2}{*}{$\begin{array}{c}\text { z-statistic } \\
\text { of } \\
\text { difference } \\
\text { in } \\
\text { medians } \\
\end{array}$} \\
\hline & Mean & Median & Mean & Median & & \\
\hline $\mathrm{MVE}_{\mathrm{t}-1}$ & 8,845 & 1,312 & 4,369 & 867 & $14.65 * * *$ & $21.43 * * *$ \\
\hline $\mathrm{ROA}_{\mathrm{t}-1}$ & 0.01 & 0.01 & 0.01 & 0.01 & $9.95 * * *$ & $10.34 * * *$ \\
\hline $\mathrm{MTB}_{\mathrm{t}-1}$ & 3.22 & 2.57 & 3.49 & 2.28 & 1.35 & $9.24 * * *$ \\
\hline Leverage $_{t-1}$ & 0.53 & 0.53 & 0.50 & 0.49 & $10.45^{* * *}$ & $11.72 * * *$ \\
\hline $\mathrm{Age}_{\mathrm{t}-1}$ & 19.48 & 11 & 17.7 & 11 & $7.34 * * *$ & $-4.22 * * *$ \\
\hline Beta & 1.11 & 1.06 & 1.11 & 1.06 & 0.66 & -0.29 \\
\hline Uearn_Vol ${ }^{1}$ & 0.017 & 0.01 & 0.02 & 0.01 & $-9.69 * * *$ & $-3.31 * * *$ \\
\hline Perc_inst ${ }^{2}$ & 0.61 & 0.64 & 0.53 & 0.56 & $26.11 * * *$ & $23.84 * * *$ \\
\hline Anal_fol ${ }^{2}$ & 10.37 & 9.00 & 8.17 & 6.00 & $22.71 * * *$ & $24.69 * * *$ \\
\hline Sharinst_net & -0.002 & 0 & -0.001 & 0 & $-3.29 * * *$ & $-1.67 * *$ \\
\hline
\end{tabular}

All variables are described in Appendix 2.B

$* * *, * *, *$ denote significance levels of $0.01,0.05$, and 0.1 , respectively.

${ }^{1}$-Estimation of volatility of unexpected earnings requires at least 12 quarters of unexpected earnings. This requirement results in only 9,714 and 9,327 forecasting and non-forecasting observations, respectively, available for this variable

2-to minimize number of lost observations, I do not require that each forecasting and nonforecasting firm has institutional ownership from CDA, and analyst data from IBES, available. Accordingly, the statistics above are reported as follows: anal fol variable-11,471 forecasting firm observations, and 9,622 non-forecasting firm observations, Perc_inst variable: 11,455 forecasting firm observations and 10,563 non-forecasting firm observations. Non-parametric tests of comparisons of sample means and medians are adjusted for differences in sample sizes. 
Table 3: Short-term forecasting window univariate liquidity tests

This table summarizes the univariate tests of the differences in medians of bid-ask spreads/depths/illiquidity/volume of the forecasting and nonforecasting firms during the pre- and post-forecast periods, and changes therein. Pre- and post-forecast periods are defined using five, ten, and 22 trading days windows around management earnings forecast date, excluding 3 day window immediately around that date. To be included in calculation, each firm-forecast combination is required to have at least $75 \%$ trading days data available in each respective window. Sample selection procedure is further described in Panel A of Table 1. 12,207 forecasting and 12,207 non-forecasting firm-forecast combinations are included in this analysis. $*, * *, * * *$ denote statistical significance levels at $0.1,0.05$, and 0.01 levels, respectively.

Panel A

\begin{tabular}{|c|c|c|c|c|c|c|c|c|c|}
\hline & \multicolumn{6}{|c|}{ Panel A } & \multicolumn{3}{|c|}{ Panel B } \\
\hline & \multicolumn{3}{|c|}{$\begin{array}{l}\text { Short-window } \\
\text { Pre-forecasting period }\end{array}$} & \multicolumn{3}{|c|}{$\begin{array}{l}\text { Short-window } \\
\text { Post-forecasting period }\end{array}$} & \multicolumn{3}{|c|}{$\begin{array}{c}\text { Change between short-window pre- } \\
\text { and post-forecasting periods }\end{array}$} \\
\hline & $\begin{array}{l}\text { Forecasting } \\
\text { firms }\end{array}$ & $\begin{array}{l}\text { Non- } \\
\text { forecasting } \\
\text { firms }\end{array}$ & z-stat ${ }^{1}$ & $\begin{array}{l}\text { Forecasting } \\
\text { firms }\end{array}$ & $\begin{array}{l}\text { Non- } \\
\text { forecasting } \\
\text { firms }\end{array}$ & z-stat ${ }^{1}$ & $\begin{array}{l}\text { Forecasting } \\
\text { firms }\end{array}$ & $\begin{array}{l}\text { Non- } \\
\text { forecasting } \\
\text { firms }\end{array}$ & z-stat ${ }^{1}$ \\
\hline \multicolumn{10}{|l|}{$\begin{array}{c}\text { Five-day window } \\
\text { around MEF } \\
\text { Date }\end{array}$} \\
\hline Quoted Mean & & & & & & & & & \\
\hline Daily Half-Spread & 0.04 & 0.05 & $-17.24 * * *$ & 0.04 & 0.05 & $-20.50 * * *$ & $-4 \%$ & $-1 \%$ & $-9.06 * * *$ \\
\hline Quoted Depth & 2,250 & 1,987 & $15.01 * * *$ & 2,346 & 1,996 & $19.03 * * *$ & $3 \%$ & $-0 \%$ & $8.97 * * *$ \\
\hline Illiq & 0.05 & 0.12 & $-31.43 * * *$ & 0.04 & 0.11 & $-36.67 * * *$ & $-15 \%$ & $-3 \%$ & $-9.5 * * *$ \\
\hline $\begin{array}{c}\text { Turn } \\
\text { Ten-day window } \\
\text { around MEF } \\
\text { Date }\end{array}$ & 4.83 & 3.76 & $20.27 * * *$ & 5.8 & 3.85 & $29.63 * * *$ & $13 \%$ & $-0 \%$ & $13.75 * * *$ \\
\hline Quoted Mean & & & & & & & & & \\
\hline Daily Half-Spread & 0.04 & 0.05 & $-17.81 * * *$ & 0.04 & 0.05 & $-20.9 * * *$ & $-4 \%$ & $-1 \%$ & $-11.03 * * *$ \\
\hline Quoted Depth & 2,323 & 2,000 & $15.09 * * *$ & 2,379 & 2,000 & $18.33 * * *$ & $1 \%$ & $-1 \%$ & $10.22 * * *$ \\
\hline Illiq & 0.06 & 0.13 & $-33.66 * * *$ & 0.05 & 0.13 & $-37.71 * * *$ & $-11 \%$ & $-4 \%$ & $-10.19 * * *$ \\
\hline $\begin{array}{c}\text { Turn } \\
\text { 22-day window } \\
\text { around MEF } \\
\text { Date }\end{array}$ & 5.13 & 4.02 & $20.89 * * *$ & 5.72 & 4.07 & $27.38^{* * *}$ & $7 \%$ & $-0 \%$ & $9.62 * * *$ \\
\hline $\begin{array}{c}\text { Quoted Mean } \\
\text { Daily Half-Spread }\end{array}$ & 0.04 & 0.05 & $-18.17 * * *$ & 0.04 & 0.05 & $-20.5 * * *$ & $-5 \%$ & $-3 \%$ & $-8.84 * * *$ \\
\hline
\end{tabular}




$\begin{array}{cccccccccc}\text { Quoted Depth } & 2,373 & 2,018 & 15.66^{* * *} & 2,399 & 2,004 & 17.64^{* * *} & 0 \% & -1 \% & 7.25^{* * *} \\ \text { Illiq } & 0.07 & 0.15 & -34.57^{* * *} & 0.06 & 0.14 & -36.56^{* * *} & -8 \% & -4 \% & -6.56^{* * *} \\ \text { Turn } & 5.32 & 4.18 & 22.16^{* * *} & 5.58 & 4.19 & 25.32^{* * *} & 4 \% & 0 \% & 4.55^{* * *}\end{array}$

All variables are described in Appendix B.

${ }^{1}$-Wilcoxon rank-sum test of difference in medians of two samples

${ }^{2}$-Two-sided Signed-rank test 


\section{Table 4: Short-term forecasting window multivariate liquidity tests}

Panel A: Pre-forecast period liquidity levels' tests

This table summarizes OLS regressions exploring the differences in levels in pre-forecast bid-ask spreads/depths/Amihud Illiquidity/Trading Volume of the forecasting and non-forecasting firms. The estimation is done using OLS with clustered standard errors and time fixed effects. Pre- and post-forecast periods are defined using 22 trading days windows around management earnings forecast date, excluding 3 day window immediately around that date. To be included in calculation, each firm-forecast combination is required to have at least $75 \%$ trading days data available in each respective window. Sample selection procedure is further described in Panel A of Table 1. 5,330 forecasting and 5,330 non-forecasting firm-forecast combinations are included in this analysis. *,**,*** denote statistical significance levels at $0.1,0.05$, and 0.01 levels, respectively.

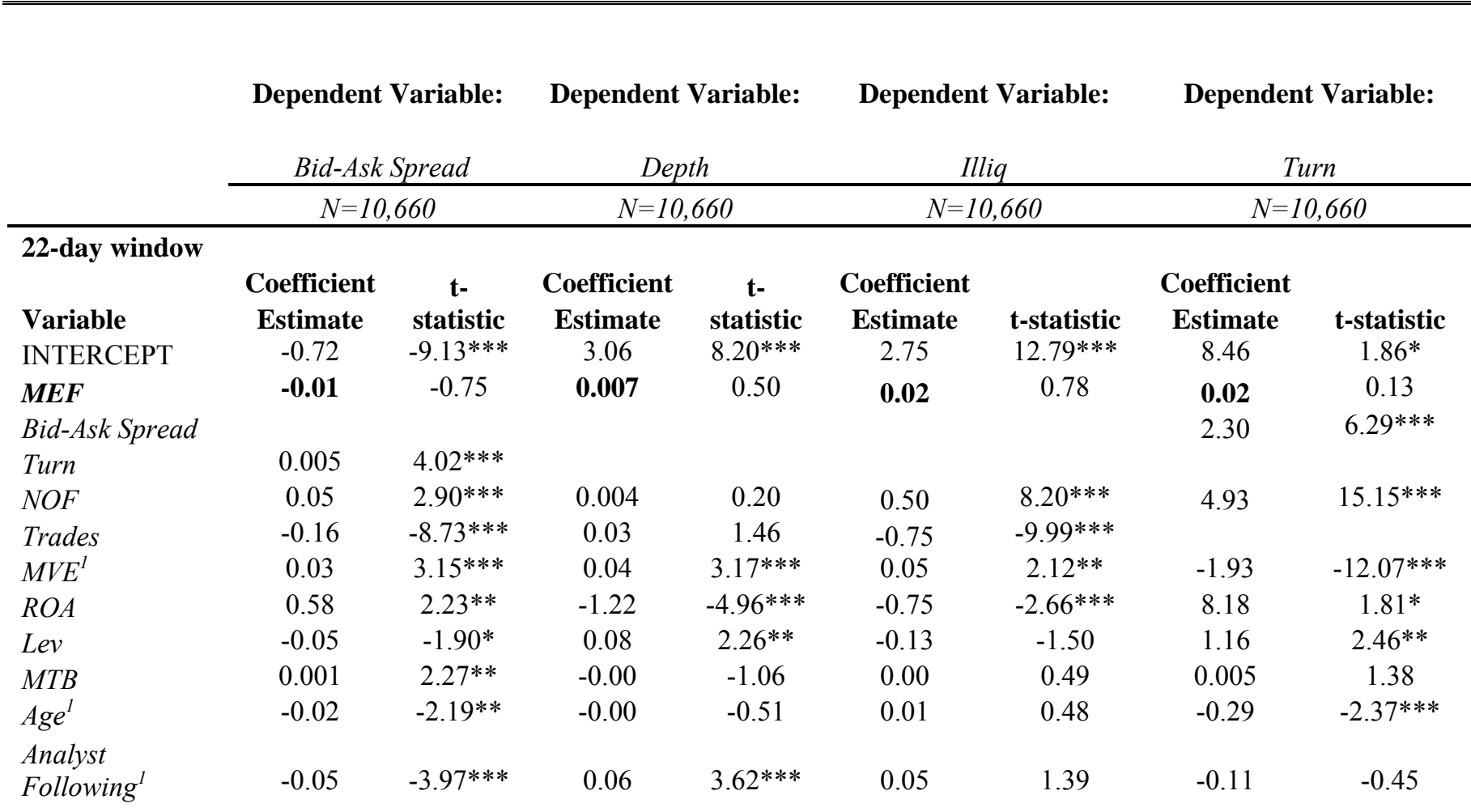




\begin{tabular}{|c|c|c|c|c|c|c|c|c|}
\hline $\begin{array}{l}\text { Earnings } \\
\text { Volatility }\end{array}$ & -0.40 & $-2.25^{* *}$ & 0.14 & 0.49 & 0.35 & 0.81 & -0.28 & -0.06 \\
\hline Beta & -0.02 & $-2.05 * *$ & 0.04 & $2.57 * * *$ & 0.02 & 0.49 & 0.22 & 0.95 \\
\hline Perc_Inst & -0.02 & -0.48 & -0.17 & $-3.78 * * *$ & -0.60 & $-4.89 * * *$ & 3.35 & $5.48^{* * *}$ \\
\hline Sharins_net & 0.34 & 1.62 & -0.71 & $-1.75^{*}$ & 1.36 & $1.82 *$ & 1.50 & 0.80 \\
\hline Litigate & 0.01 & 0.82 & 0.01 & 0.66 & 0.09 & $2.01 * *$ & 0.61 & $2.28 * *$ \\
\hline$F D^{\circ}$ & -0.05 & $-2.15^{* *}$ & 0.02 & 0.50 & 0.007 & 0.12 & -0.46 & -1.22 \\
\hline Prior spread $^{l}$ & 0.46 & $11.09 * * *$ & & & 0.30 & $3.89 * * *$ & & \\
\hline Prior depth ${ }^{l}$ & & & 0.64 & $41.40 * * *$ & & & & \\
\hline Prior turnover ${ }^{l}$ & & & & & & & 0.47 & $8.10^{* * *}$ \\
\hline Event & 0.01 & 1.61 & 0.02 & 1.10 & 0.005 & 0.20 & 0.09 & 0.52 \\
\hline$R^{2}$ & & 0.79 & & 0.76 & & 0.33 & & 0.61 \\
\hline
\end{tabular}

\section{All variables are described in Appendix B.}

${ }^{1}$-Logarithmic transformation is used in this specification. 
Table 4: Short-term forecasting window multivariate liquidity tests

Panel B: Liquidity changes' tests

This table summarizes OLS regressions exploring the differences in changes in levels of pre-forecast bid-ask spreads/depths/Amihud Illiquidity of the forecasting and non-forecasting firms. The estimation is done using OLS with clustered standard errors and time fixed effects. Pre- and post-forecast periods are defined using 22 trading days windows around management earnings forecast date, excluding 3 day window immediately around that date. To be included in calculation, each firm-forecast combination is required to have at least $75 \%$ trading days data available in each respective window. Sample selection procedure is further described in Panel A of Table 1. 5,330 forecasting and 5,330 non-forecasting firm-forecast combinations are included in this analysis. *, **, *** denote statistical significance levels at $0.1,0.05$, and 0.01 levels, respectively.

Dependent Variable: Dependent Variable: Dependent Variable: Dependent Variable:

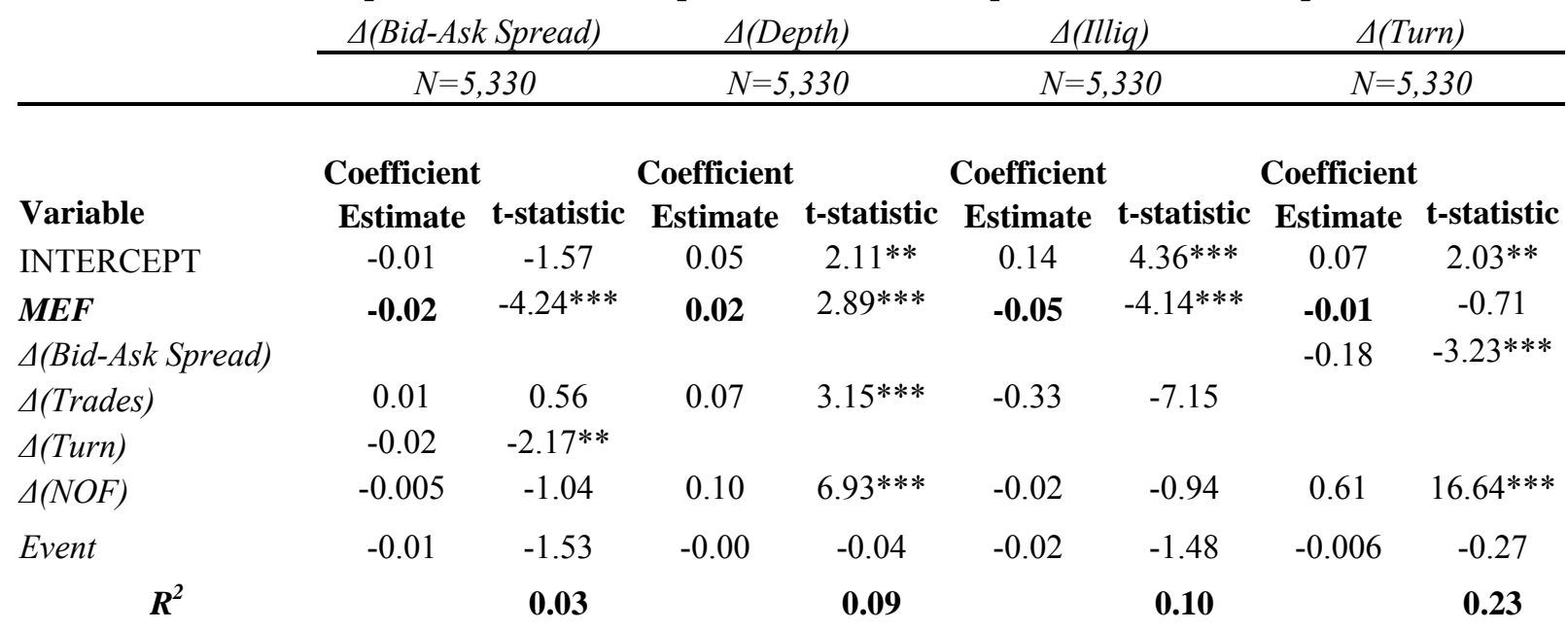

All variables are defined in Appendix B 
Table 5: Long-term forecasting window univariate liquidity tests

This table summarizes the univariate tests of the differences in medians of bid-ask spreads/depths/illiquidity/volume of the forecasting and nonforecasting firms during the pre- and post-forecast periods, and changes therein. Pre- and post-forecast periods are defined using 62 , 125 , and 250 trading day windows around management earnings forecast date, excluding 3 day window immediately around that date. To be included in calculation, each firm-forecast combination is required to have at least $75 \%$ trading day data available in each respective window. Sample selection procedure is further described in Panel A of Table 1. 12,207 forecasting and 12,207 non-forecasting firm-forecast combinations are included in this analysis. $*, * *, * * *$ denote statistical significance levels at $0.1,0.05$, and 0.01 levels, respectively.

\section{2-day window} around MEF Date

Quoted Mean

Daily Half-

$$
\text { Spread }
$$

Quoted Depth

Illiq

Turn

125-day

window around

MEF Date

Quoted Mean

Daily Half-

Spread

Quoted Depth

Illiq

Turn

250-day

window around

MEF Date
Panel A

\begin{tabular}{cc}
\hline Long-window & Long-window \\
Pre-forecasting period & Post-forecasting period \\
\hline
\end{tabular}

Panel B

Change between long-window preand post-forecasting periods

$\begin{array}{cccccc}\text { Forecasting } & \begin{array}{c}\text { Non- } \\ \text { forecasting }\end{array} & & \text { Forecasting } & \begin{array}{c}\text { Non- } \\ \text { forecasting }\end{array} & \\ \text { firms } & \text { firms } & \text { z-stat }^{1} & \text { firms } & \text { firms } & \text { z-stat }\end{array}$

Forecasting forecasting

firms firms $\quad$-stat $^{1}$

\begin{tabular}{|c|c|c|c|c|c|c|c|c|}
\hline 0.04 & 0.05 & $-18.39 * * *$ & 0.04 & 0.05 & $-20.28 * * *$ & $-10 \%$ & $-8 \%$ & $-8.62 * * *$ \\
\hline 2,414 & 2,058 & $15.94 * * *$ & 2,369 & 2,002 & $16.93 * * *$ & $-2 \%$ & $-4 \%$ & $4.16^{* * *}$ \\
\hline 0.07 & 0.15 & $-35.37 * * *$ & 0.06 & 0.14 & $-35.19 * * *$ & $-7 \%$ & $-7 \%$ & -0.17 \\
\hline 5.56 & 4.31 & $23.29 * * *$ & 5.72 & 4.40 & $23.41 * * *$ & $1.3 \%$ & $0.8 \%$ & -0.51 \\
\hline 0.05 & 0.06 & $-18.22 * * *$ & 0.03 & 0.05 & $-20.45 * * *$ & $-17 \%$ & $-15 \%$ & $-9.28 * * *$ \\
\hline 2,480 & 2,107 & $15.96 * * *$ & 2,343 & 2,000 & $16.60 * * *$ & $-7 \%$ & $-7 \%$ & $3.14 * * *$ \\
\hline 0.07 & 0.16 & $-35.27 * * *$ & 0.06 & 0.14 & $-34.69 * * *$ & $-12 \%$ & $-12 \%$ & 0.66 \\
\hline 5.61 & 4.4 & $22.83 * * *$ & 5.8 & 4.58 & $22.89 * * *$ & $3.8 \%$ & $0.8 \%$ & -0.00 \\
\hline
\end{tabular}


Quoted Mean

Daily HalfSpread

Quoted Depth

$\begin{array}{cc}0.05 & 0.06 \\ 2,609 & 2,198 \\ 0.08 & 0.17 \\ 5.56 & 4.52\end{array}$

$\begin{array}{cc}-18.37 * * * & 0.03 \\ 16.33 * * * & 2,292 \\ -34.52 * * * & 0.06 \\ 21.49 * * * & 5.90\end{array}$

0.04

$-20.87 * * *$

$-31 \%$

$-27 \%$

Illiq

5.56

4.52

$21.49 * * *$

5.90

0.13

4.78

$16.02 * * *$

$-34.09 * * *$

$-14 \%$

$-20 \%$

$10 \%$

$-14 \%$

$-19 \%$

$21.88 * * *$

$4 \%$

$-0.28$

All variables are described in Appendix B.

${ }^{1}$-Wilcoxon rank-sum test of difference in medians of two samples

${ }^{2}$-Two-sided Signed-rank test 


\section{Table 6: Long-term forecasting window multivariate liquidity tests}

This table summarizes the multivariate tests of the differences in medians of bid-ask spreads/depths/illiquidity/volume of the forecasting and nonforecasting firms during the pre- and post-forecast periods, and changes therein. The estimation is done using OLS with clustered standard errors and time fixed effects. Pre- and post-forecast periods are defined using 125 trading days windows around management earnings forecast date, excluding 3 day window immediately around that date To be included in calculation, each firm-forecast combination is required to have at least $75 \%$ trading day data available in each respective window. Sample selection procedure is further described in Panel A of Table 1. 5,330 forecasting and 5,330 non-forecasting firm-forecast combinations are included in this analysis. *,**,*** denote statistical significance levels at $0.1,0.05$, and 0.01 levels, respectively.

Panel A: Pre-forecast period liquidity levels' tests

\begin{tabular}{|c|c|c|c|c|c|c|c|c|}
\hline \multirow[b]{4}{*}{ Variable } & \multicolumn{2}{|c|}{$\begin{array}{l}\text { Model 1b: Dependent } \\
\text { Variable: }\end{array}$} & \multicolumn{2}{|c|}{$\begin{array}{c}\text { Model 2b: Dependent } \\
\text { Variable: }\end{array}$} & \multicolumn{2}{|c|}{$\begin{array}{c}\text { Model 3b: Dependent } \\
\text { Variable: }\end{array}$} & \multicolumn{2}{|c|}{$\begin{array}{c}\text { Model 3b: Dependent } \\
\text { Variable: }\end{array}$} \\
\hline & \multicolumn{2}{|c|}{ Bid-Ask Spread ${ }^{l}$} & \multicolumn{2}{|c|}{$D_{e p t h}^{l}$} & \multicolumn{2}{|c|}{ Illiq } & \multicolumn{2}{|c|}{ Turn } \\
\hline & Coefficient & & Coefficient & & Coefficient & & Coefficient & \\
\hline & Estimate & t-statistic & Estimate & t-statistic & Estimate & t-statistic & Estimate & t-statistic \\
\hline INTERCEPT & -0.64 & $-7.87 * * *$ & 2.82 & $9.00 * * *$ & 3.10 & $14.34 * * *$ & 6.81 & $6.78 * * *$ \\
\hline MEF & -0.005 & -0.53 & 0.006 & 0.52 & 0.03 & 1.00 & -0.02 & -0.15 \\
\hline Bid-Ask Spread $^{l}$ & & & & & & & 2.67 & $7.72 * * *$ \\
\hline Turn & 0.006 & $4.98 * * *$ & & & & & & \\
\hline$N O F^{l}$ & 0.08 & $3.59 * * *$ & -0.05 & -1.62 & 1.05 & $7.95 * * *$ & 4.79 & $13.01 * * *$ \\
\hline Trades ${ }^{I}$ & -0.20 & $-8.90 * * *$ & 0.04 & 1.46 & -1.18 & $-8.73 * * *$ & & \\
\hline$M V E^{l}$ & 0.05 & $4.11 * * *$ & 0.04 & $4.68 * * *$ & 0.04 & 1.62 & -1.94 & $-11.26^{* * *}$ \\
\hline$R O A$ & 0.50 & $1.82 *$ & -1.04 & $-6.24 * * *$ & -0.93 & $-2.98 * * *$ & 1.50 & 0.37 \\
\hline Lev & -0.06 & $-2.69 * *$ & 0.07 & $2.13 * * *$ & -0.06 & -0.66 & 1.35 & $2.63 * * *$ \\
\hline$M T B$ & 0.001 & $2.48 * *$ & -0.00 & -1.51 & 0.00 & 0.47 & 0.002 & 0.85 \\
\hline$A g e^{1}$ & -0.02 & $-2.60 * *$ & 0.001 & 0.17 & 0.05 & $2.12 * *$ & -0.23 & -2.02 \\
\hline Analyst Following $^{l}$ & -0.04 & $-3.59 * * *$ & 0.07 & $4.64 * * *$ & 0.07 & 1.6 & 0.09 & 0.37 \\
\hline Earnings Volatility & -0.32 & $-2.24 * * *$ & 0.06 & 0.22 & 0.54 & 1.08 & 1.05 & 0.24 \\
\hline Beta & -0.02 & $-1.90 *$ & 0.03 & $2.33 * *$ & 0.01 & 0.39 & 0.32 & 1.46 \\
\hline Perc_Inst & -0.02 & -0.58 & -0.15 & $-3.80 * * *$ & -0.58 & -4.52 & 3.24 & $5.77 * * *$ \\
\hline Sharins_net & 0.39 & $2.12 * *$ & -0.65 & $-2.40 * *$ & 1.92 & 1.53 & 1.42 & 1.04 \\
\hline
\end{tabular}




\begin{tabular}{|c|c|c|c|c|c|c|c|c|}
\hline Litigate & 0.02 & 1.42 & 0.01 & 0.47 & 0.09 & $1.86^{*}$ & 0.43 & $1.75^{*}$ \\
\hline$F D$ & -0.06 & $-3.35 * * *$ & 0.02 & 0.62 & -0.03 & -0.46 & -0.21 & -0.68 \\
\hline Prior spread & 0.49 & $10.45 * * *$ & & & 0.39 & $4.92 * * *$ & & \\
\hline Prior depth ${ }^{l}$ & & & 0.66 & $55.23^{* * *}$ & & & & \\
\hline Prior turn & & & & & & & 0.52 & $9.38 * * *$ \\
\hline Event & 0.02 & $2.52 * *$ & 0.02 & 1.21 & -0.005 & -0.21 & -0.11 & -0.83 \\
\hline$R^{2}$ & & 0.82 & & 0.81 & & 0.37 & & 0.72 \\
\hline
\end{tabular}

All Variables are defined in Appendix B

${ }^{1-}$ Logarithmic transformation is used 


\section{Table 6: Long-term forecasting window multivariate liquidity tests}

This table summarizes the multivariate tests of the differences in changes of means of bid-ask spreads/depths/illiquidity/volume of the forecasting and non-forecasting firms between pre-forecasting and post-forecasting periods. The estimation is done using OLS with clustered standard errors and time fixed effects. Pre- and post-forecast periods are defined using 125 trading days windows around management earnings forecast date, excluding 3 day window immediately around that date To be included in calculation, each firm-forecast combination is required to have at least $75 \%$ trading day data available in each respective window. Sample selection procedure is further described in Panel A of Table $1.5,330$ forecasting and 5,330 non-forecasting firm-forecast combinations are included in this analysis. $*, * *, * * *$ denote statistical significance levels at $0.1,0.05$, and 0.01 levels, respectively.

Panel B: Changes in liquidity levels' tests

\begin{tabular}{|c|c|c|c|c|c|c|c|c|}
\hline & \multirow{2}{*}{\multicolumn{2}{|c|}{$\begin{array}{c}\text { Model 1: Dependent } \\
\text { Variable: } \\
\Delta(\text { Bid-Ask Spread })\end{array}$}} & \multirow{2}{*}{\multicolumn{2}{|c|}{$\begin{array}{c}\text { Model 3: Dependent } \\
\text { Variable: } \\
\Delta(\text { Depth }) \\
\end{array}$}} & \multirow{2}{*}{\multicolumn{2}{|c|}{$\begin{array}{c}\text { Model 2: Dependent } \\
\text { Variable: } \\
\Delta(\text { Illiq }) \\
\end{array}$}} & \multirow{2}{*}{\multicolumn{2}{|c|}{$\begin{array}{c}\text { Model 2: Dependent } \\
\text { Variable: } \\
\Delta(\text { Volume })\end{array}$}} \\
\hline & & & & & & & & \\
\hline & \multicolumn{2}{|c|}{$N=5,330$} & \multicolumn{2}{|c|}{$N=5,330$} & \multicolumn{2}{|c|}{$N=5,330$} & \multicolumn{2}{|c|}{$N=5,330$} \\
\hline Variable & $\begin{array}{c}\text { Coefficient } \\
\text { Estimate }\end{array}$ & t-statistic & $\begin{array}{c}\text { Coefficient } \\
\text { Estimate }\end{array}$ & t-statistic & $\begin{array}{c}\text { Coefficient } \\
\text { Estimate }\end{array}$ & t-statistic & $\begin{array}{c}\text { Coefficient } \\
\text { Estimate }\end{array}$ & t-statistic \\
\hline INTERCEPT & -0.11 & $-9.17 * * *$ & -0.07 & $-2.89 * * *$ & 0.09 & $4.31 * * *$ & -0.04 & -1.40 \\
\hline$M E F$ & -0.02 & $-2.90 * * *$ & 0.008 & 0.85 & -0.006 & -0.43 & -0.03 & $-2.53 * *$ \\
\hline$\Delta$ (Bid-Ask Spread) & & & & & & & -0.01 & -0.44 \\
\hline$\Delta$ (Trades) & 0.04 & $3.79 * * *$ & -0.06 & $-4.25 * * *$ & -0.20 & $-5.54 * * *$ & & \\
\hline$\Delta($ Turn $)$ & -0.03 & $-2.94 * * *$ & & & & & & \\
\hline$\Delta(N O F)$ & -0.01 & -1.14 & 0.10 & $4.34 * * *$ & -0.18 & $-5.58 * * *$ & 0.67 & $21.62 * * *$ \\
\hline Event & -0.02 & $-2.98 * * *$ & 0.006 & 0.60 & -0.06 & $-5.78 * * *$ & 0.00 & 0.19 \\
\hline$R^{2}$ & & 0.15 & & 0.08 & & 0.31 & & 0.40 \\
\hline
\end{tabular}

All variables are defined in Appendix B 
Table 7: The effects of the Management earnings forecasts' initiation on information asymmetry

Panel A: Univariate Comparison of Information asymmetry metrics

This table summarizes the univariate tests of the changes in median bid-ask spreads/depths/illiquidity/volume of the sample of the management earnings forecast initiations. The management earnings forecast initiation is defined as the first issuance of the management earnings forecast by the firm when the firm did not issue any management earnings forecasts in the preceding 12 months. The bid-ask spreads, depths, Illiq, and volume are compared for the sample of the initiating firms in the pre-and post-initiation periods. The pre (post)-initiation period is defined as either 22 or 125 trading days prior (subsequent) to the initiating management earnings forecast date (initiation date), excluding 3 trading days before and after the initiation date (see Figure A2 in Appendix A). All initiating firms are required to have Market Microstructure transaction data, CRSP and Compustat data available. Additionally, any forecasting firms are excluded if either forecasting or matched firm has any corporate events, such as stock offerings, repurchases or bankruptcies during either pre- or postinitiation period. $* * *, * * *$ denote statistical significance levels of $0.1,0.05$, and 0.01 , respectively.

\begin{tabular}{|c|c|c|c|c|c|c|}
\hline & \multicolumn{3}{|c|}{ Pre-initiation period } & \multicolumn{3}{|c|}{$\begin{array}{l}\text { Change between short-window } \\
\text { pre- and post-forecasting periods }\end{array}$} \\
\hline & $\begin{array}{c}\text { Initiating } \\
\text { Forecasting } \\
\text { firms } \\
(\mathrm{N}=1,165)\end{array}$ & $\begin{array}{c}\text { Non- } \\
\text { forecasting } \\
\text { firms } \\
(\mathrm{N}=1,165)\end{array}$ & z-stat ${ }^{1}$ & $\begin{array}{c}\text { Initiating } \\
\text { Forecasting } \\
\text { firms } \\
(\mathrm{N}=1,165)\end{array}$ & $\begin{array}{c}\text { Non- } \\
\text { forecasting } \\
\text { firms } \\
(\mathrm{N}=1,165)\end{array}$ & $z$-stat ${ }^{1}$ \\
\hline $\begin{array}{c}\text { 22-day } \\
\text { window } \\
\text { around MEF } \\
\text { Date }\end{array}$ & & & & & & \\
\hline $\begin{array}{l}\text { Quoted Mean } \\
\text { Daily Half- }\end{array}$ & & & & & & \\
\hline Spread & 0.053 & 0.057 & $-2.59 * * *$ & $-6 \%$ & $-2 \%$ & $-4.98 * * *$ \\
\hline Quoted Depth & 1,937 & 1,985 & 0.15 & $3 \%$ & $-1 \%$ & $4.8 * * *$ \\
\hline Illiq & 0.15 & 0.20 & $4.99 * * *$ & $-10 \%$ & $-5 \%$ & $3.26 * * *$ \\
\hline Volume & 185,252 & 138,626 & $4.04 * * *$ & $9 \%$ & $1 \%$ & $3.62 * * *$ \\
\hline $\begin{array}{c}\text { 125-day } \\
\text { window } \\
\text { around MEF } \\
\text { Date }\end{array}$ & & & & & & \\
\hline $\begin{array}{l}\text { Quoted Mean } \\
\text { Daily Half- }\end{array}$ & & & & & & \\
\hline Spread & 0.059 & 0.062 & $-2.75 * * *$ & $-17 \%$ & $-16 \%$ & -1.13 \\
\hline Quoted Depth & 2,067 & 2,036 & 0.82 & $-8 \%$ & $-8 \%$ & 0.74 \\
\hline Illiq & 0.16 & 0.22 & $-4.96 * * *$ & $-14 \%$ & $-15 \%$ & -0.24 \\
\hline Volume & 183,382 & 144,444 & $4.13 * * *$ & $6 \%$ & $6 \%$ & $1.56^{*}$ \\
\hline
\end{tabular}

All variables are described in Appendix B.

${ }^{1}$-Wilcoxon rank-sum test of difference in medians of two sample 
Table 7: The effects of the Management earnings forecasts' initiation on information asymmetry

Panel B: Multivariate analysis of changes in liquidity of initiating and non-forecasting firms

The panel summarizes the analysis of changes in liquidity of initiating and non-forecasting firms between pre and post-initiation period upon management earnings forecast initiation for 1,165 initiations and control firms. The control sample consists of the non-forecasting firms in the same industry and with the closest market value of equity. The primary variable of interest is MEF which equals 1 if the firm is an initiating firm and 0 if the firm is a control firm. The changes in bid-ask spreads are measured over the pre- and post-initiation periods. The pre (post)-initiation period is defined as either 22 or 125 trading days prior (subsequent) to the initiating management earnings forecast date (initiation date), excluding 3 trading days before and after the initiation date (see Figure A2 in Appendix A). All initiating and control firms are required to have Market Microstructure transaction data, CRSP and Compustat data available. Additionally, any forecasting and control firms are excluded if either forecasting or matched firm has any corporate events, such as stock offerings, repurchases or bankruptcies during either pre- or post-initiation period. $*, * *, * *$ denote statistical significance levels of $0.1,0.05$, and 0.01 , respectively. The standard errors are adjusted for firm level clustering effects, and both models include year fixed effects to control for time-series clustering per methodology recommended in Petersen (2005).

\section{2-trading day window}

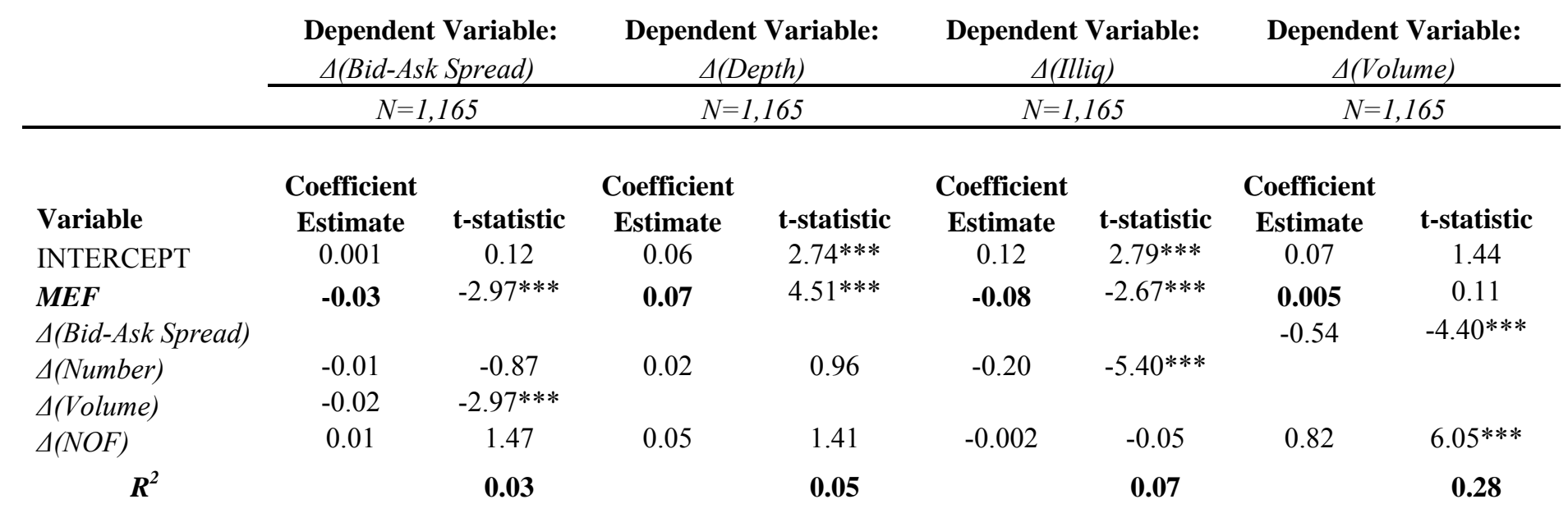


125-trading day window

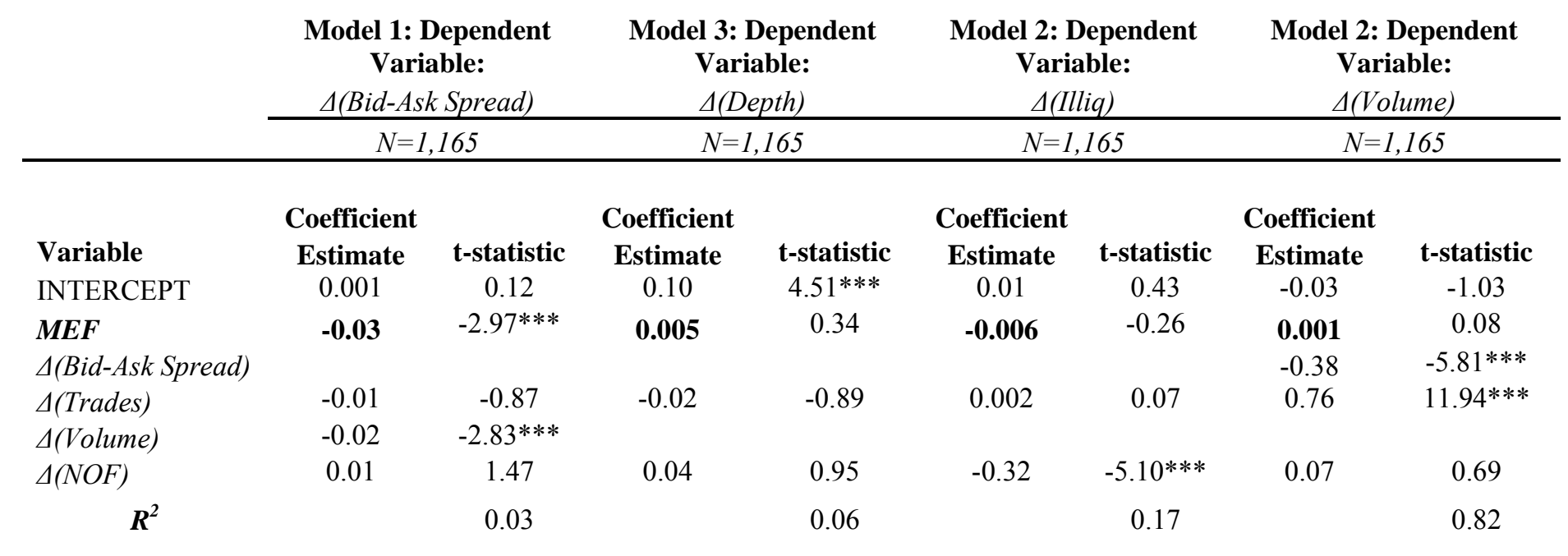

All variables are described in Appendix B. 
Table 8: The univariate tests of the effects of the Management earnings forecasts' cessation on information asymmetry

This table summarizes the univariate tests of the changes in median bid-ask spreads/depths/Illiq of the sample of the management earnings forecast cessations. The management earnings forecast cessation (stopping) is defined when a firm that issues at least 3 quarterly earnings forecasts in one year period and none in the following year.The information asymmetry metrics are compared for the sample of the stopping firms in the 62 trading day period preceding 3 days before the latest MEF (i.e. trading days -65 to -3 before the last management earnings forecast, referred to as Period 0 ) to the average spreads in depths in the 62 trading days afterwards (i.e. calendar days 3 to 65 following the last management earnings forecast, referred to as Period 1. See Figure A3 in Appendix A). All stopping firms are required to have Market Microstructure database data, CRSP and Compustat data available. Additionally, any stopping firms are excluded if they any corporate events, such as stock offerings, repurchases or bankruptcies during the quarter of the last forecast issuance.

\begin{tabular}{ccccc} 
Variable & N & $\begin{array}{c}\text { Period } \\
\mathbf{0}\end{array}$ & $\begin{array}{c}\text { Period } \\
\mathbf{1}\end{array}$ & $\begin{array}{c}\mathbf{z}- \\
\text { stat }^{1}\end{array}$ \\
\hline $\begin{array}{c}\text { Quoted Half } \\
\text { Spread }\end{array}$ & 116 & 0.027 & 0.025 & -0.79 \\
Quoted Depth & 116 & 2,159 & 2,023 & -0.73 \\
& & & & \\
Illiq & 116 & 0.08 & 0.07 & 0.16 \\
Turn & 116 & 5.78 & 5.54 & 0.57
\end{tabular}

All variables are defined in $\mathrm{B}$

${ }^{1}$-Wilcoxon rank-sum test of difference in medians of two samples 
Figure 1:

Quoted Half Spread Behavior of Forecasting and Non-Forecasting firms

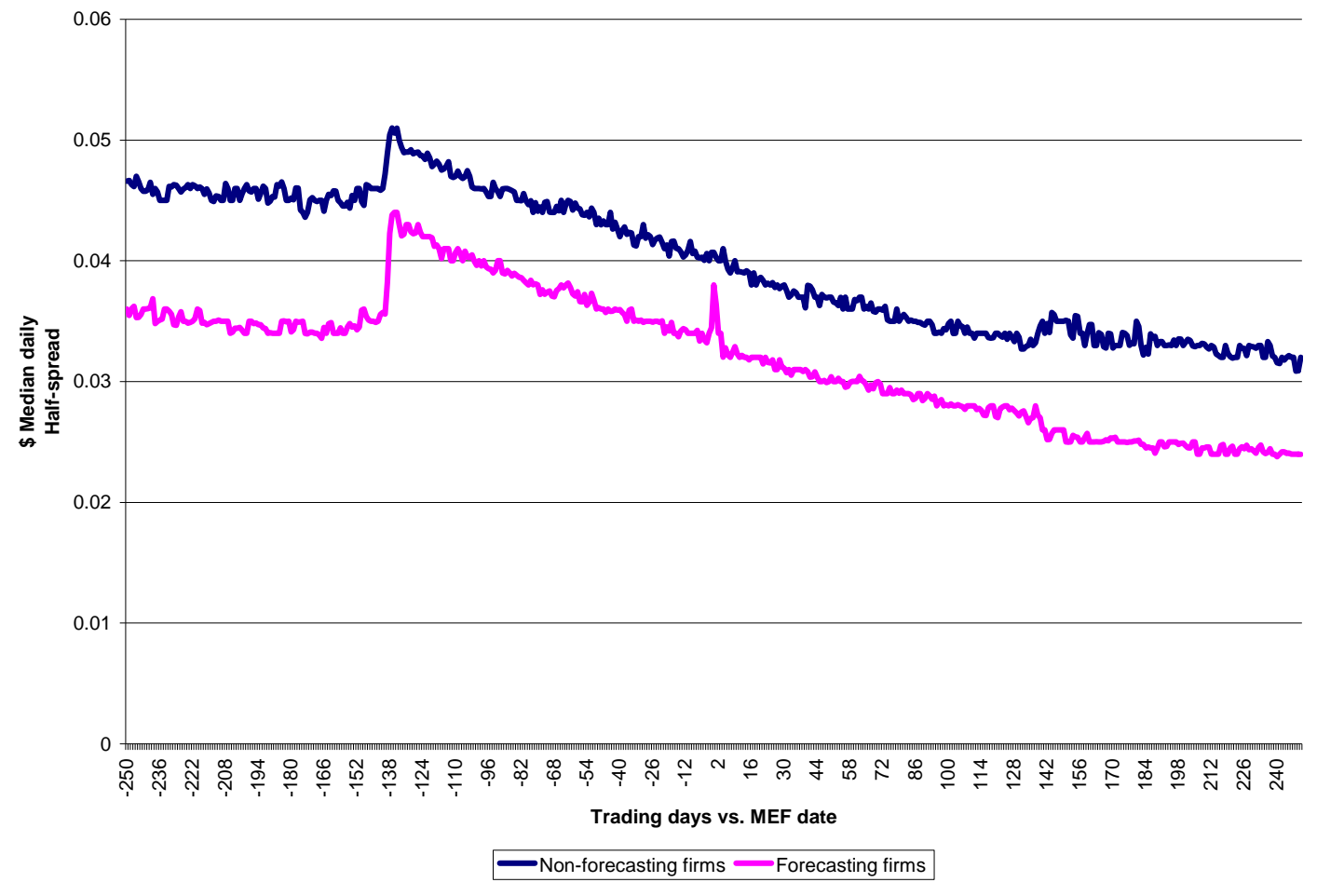

Figure 2: Quoted depth of forecasting and non-forecasting firms

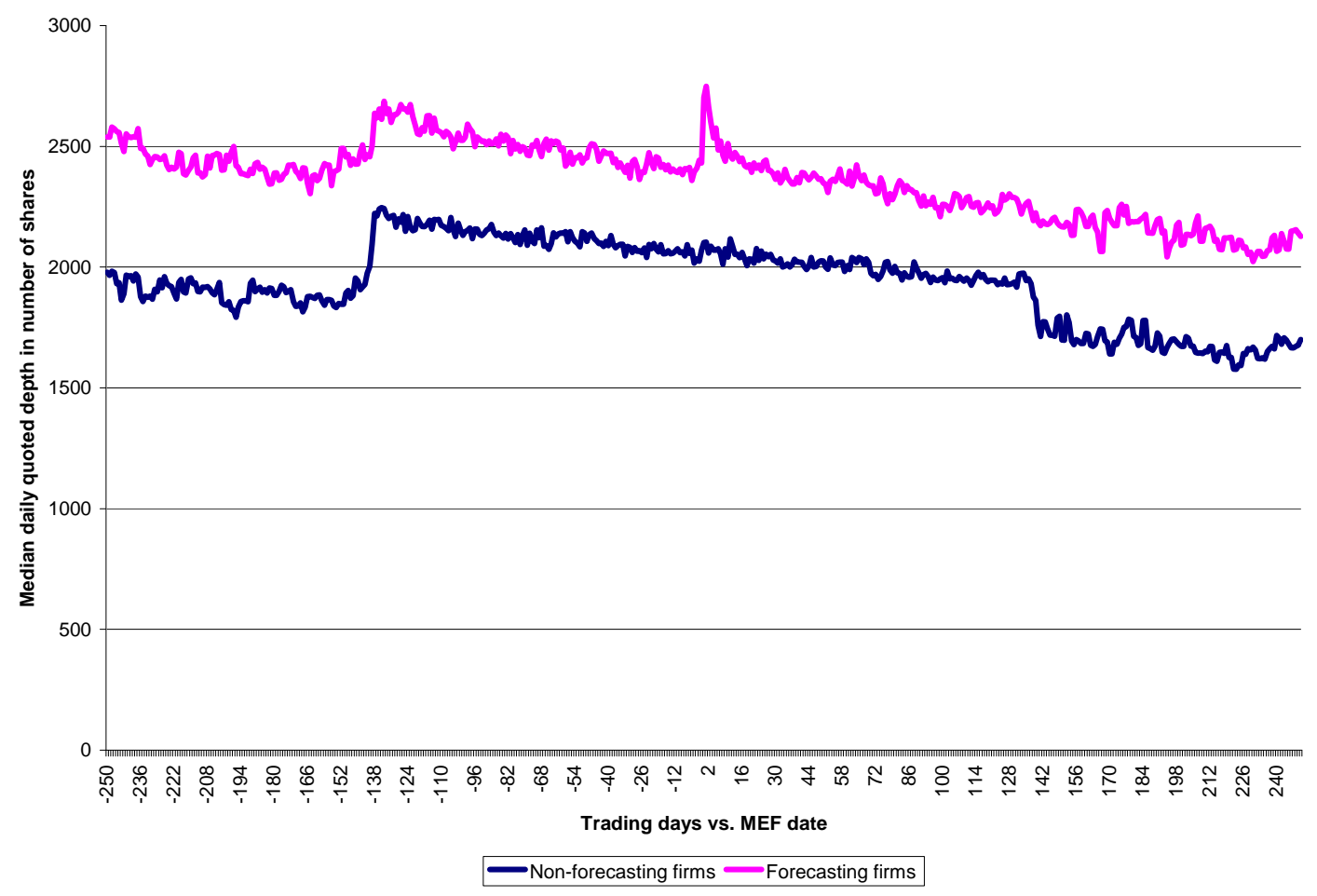


Figure 3: Amihud Illiquidity of forecasting and non-forecasting firms

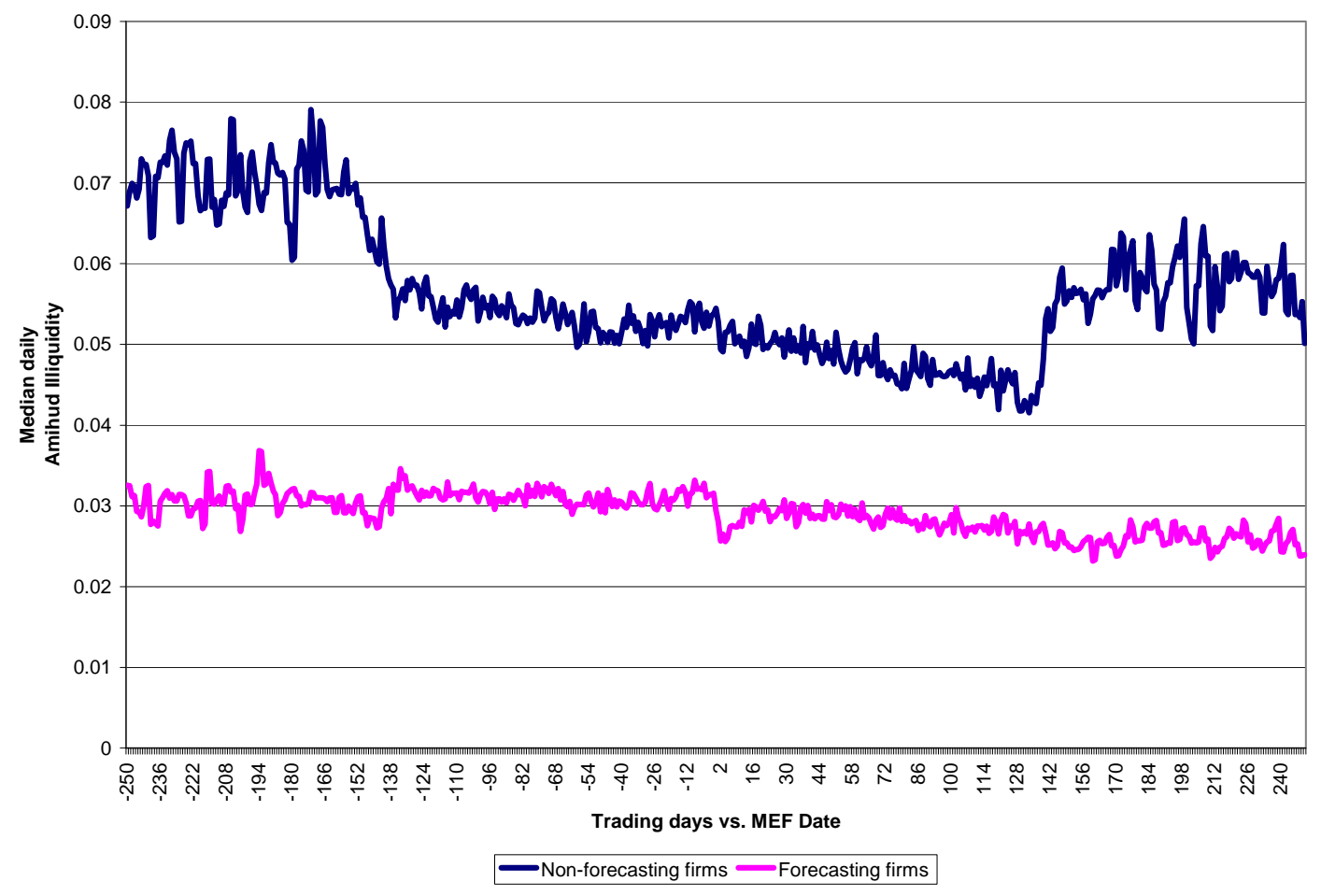

Figure 4 Share turnover (volume deflated by number of shares outstanding) of forecasting and non-forecasting firms

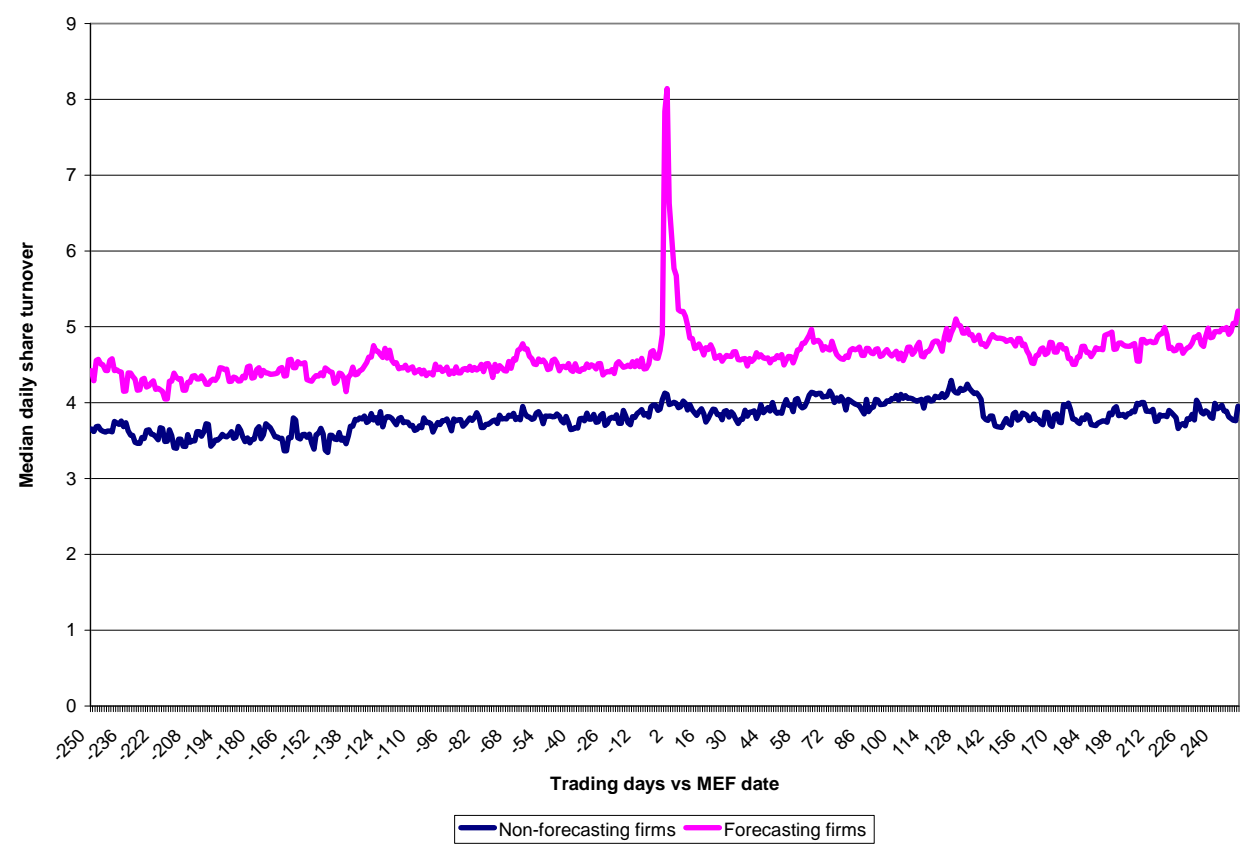


Figure 5A:

Quoted Half Spreads of Initiating and Non-forecasting Firms

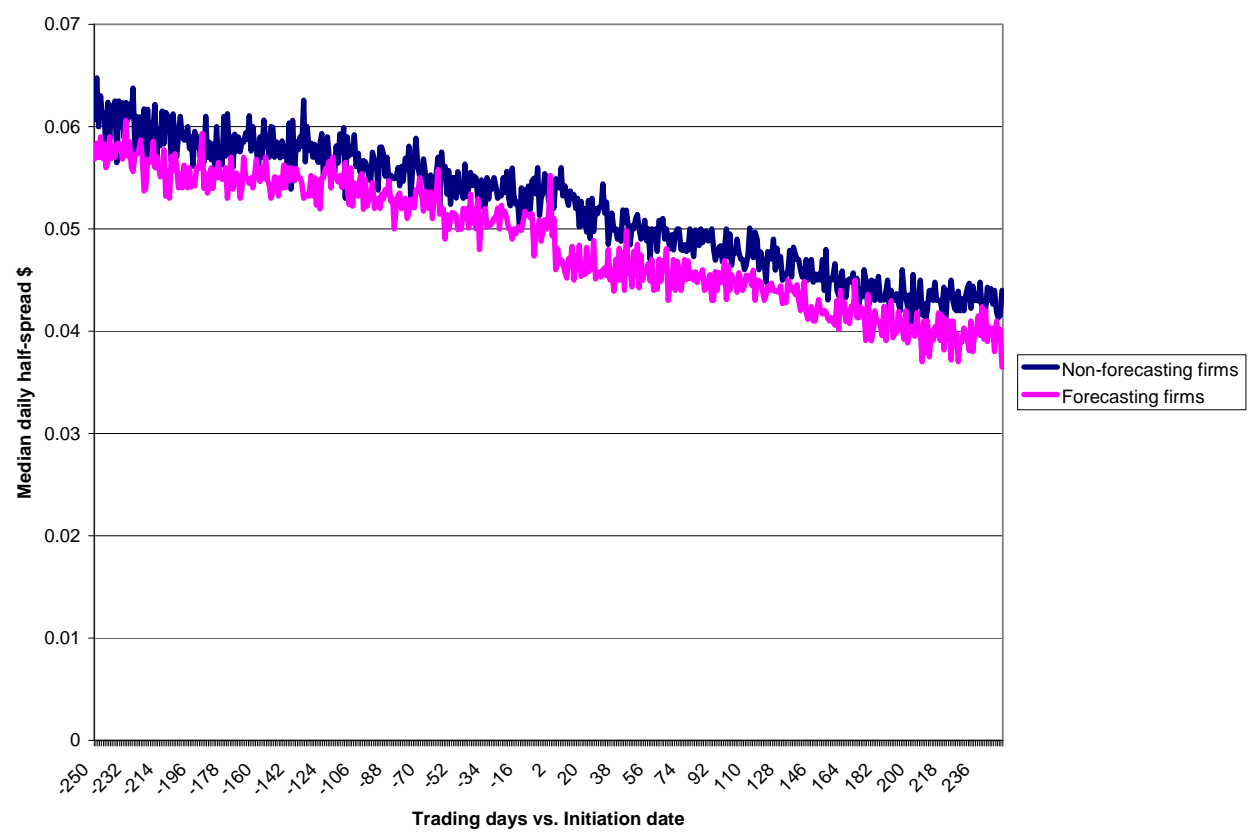

Figure B: Quoted depths of Initiating and Non-forecasting Firms

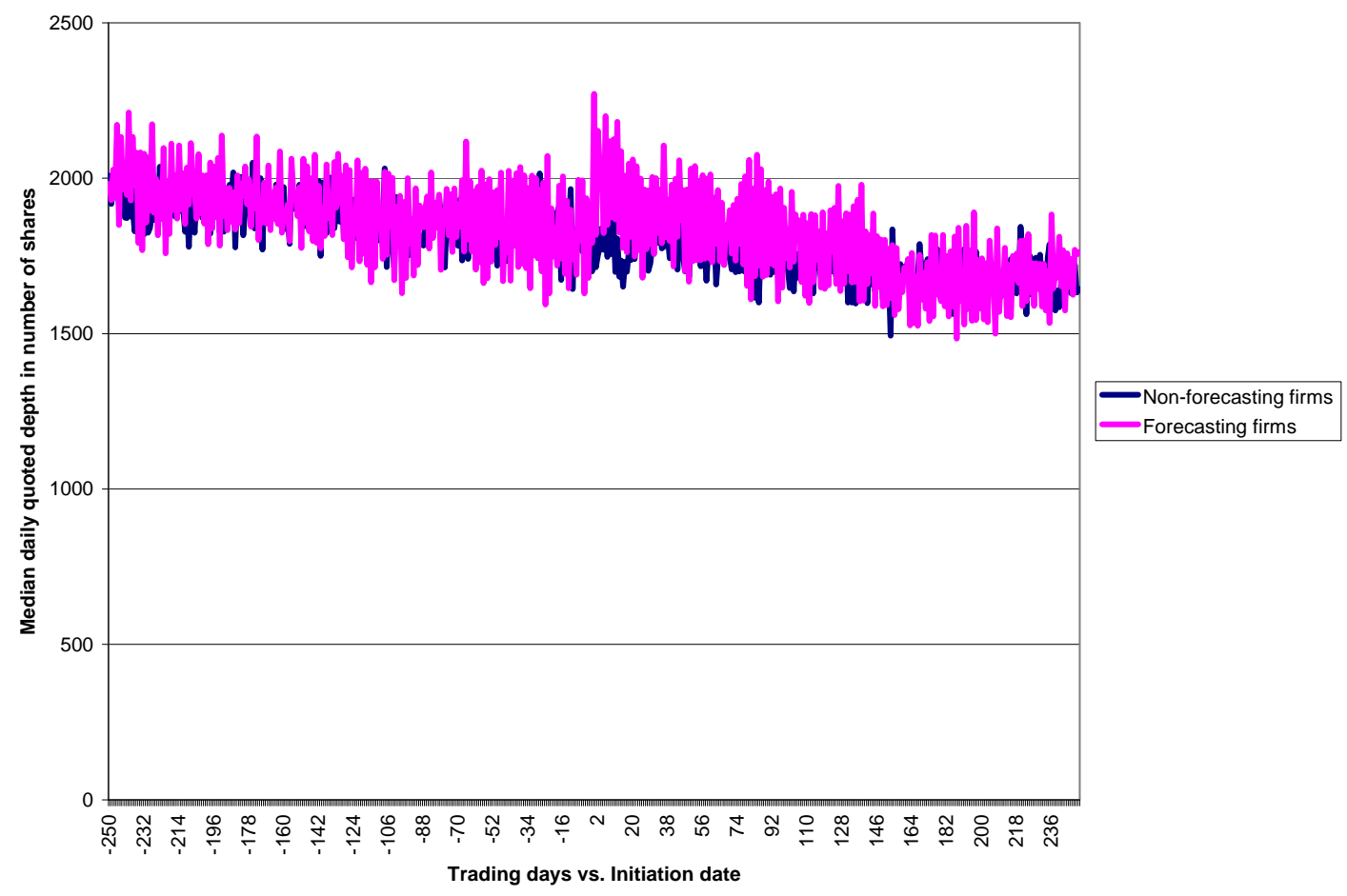


Figure 5C: Amihud Illiquidity of Initiating and Non-forecasting Firms

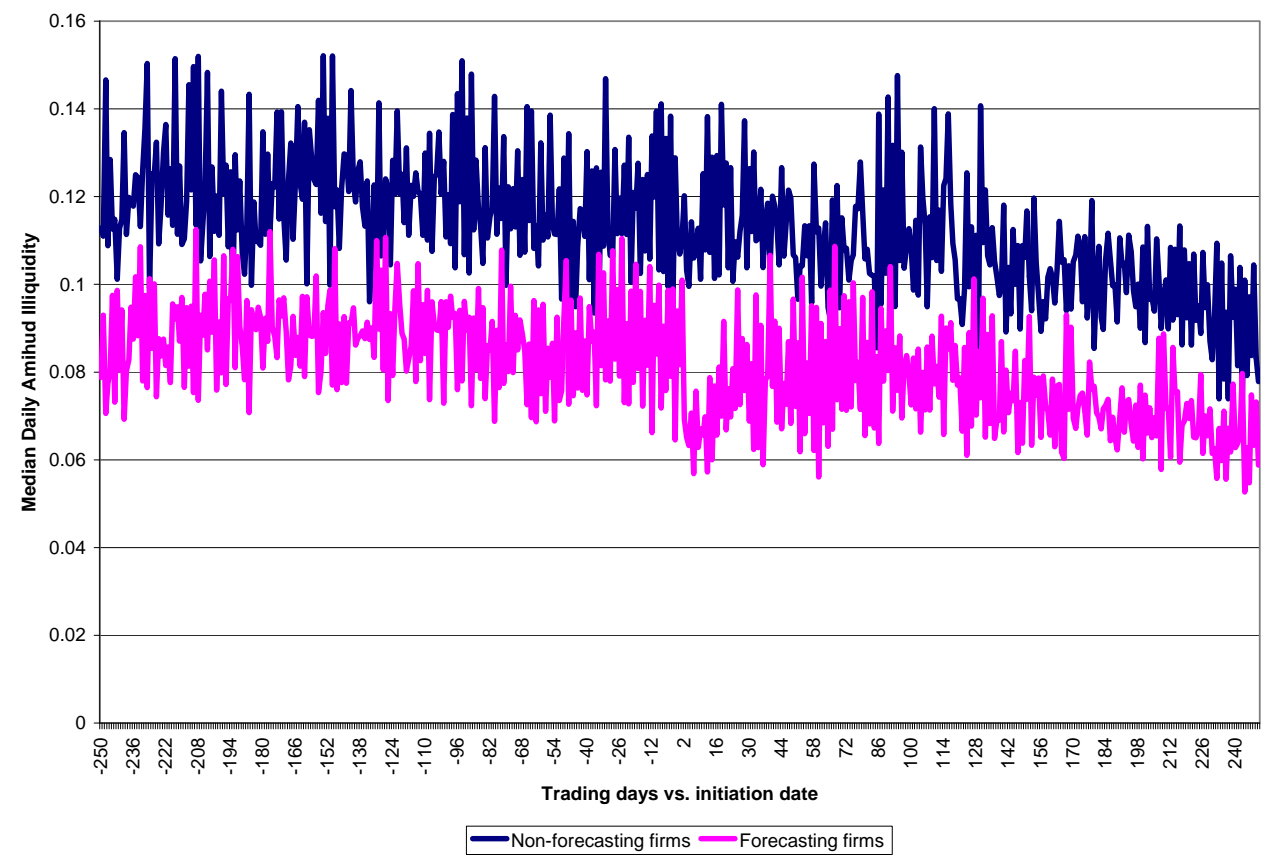

Figure 5D: Share Turnover (volume deflated by number of shares outstanding) of Initiating and Non-Forecasting Firms

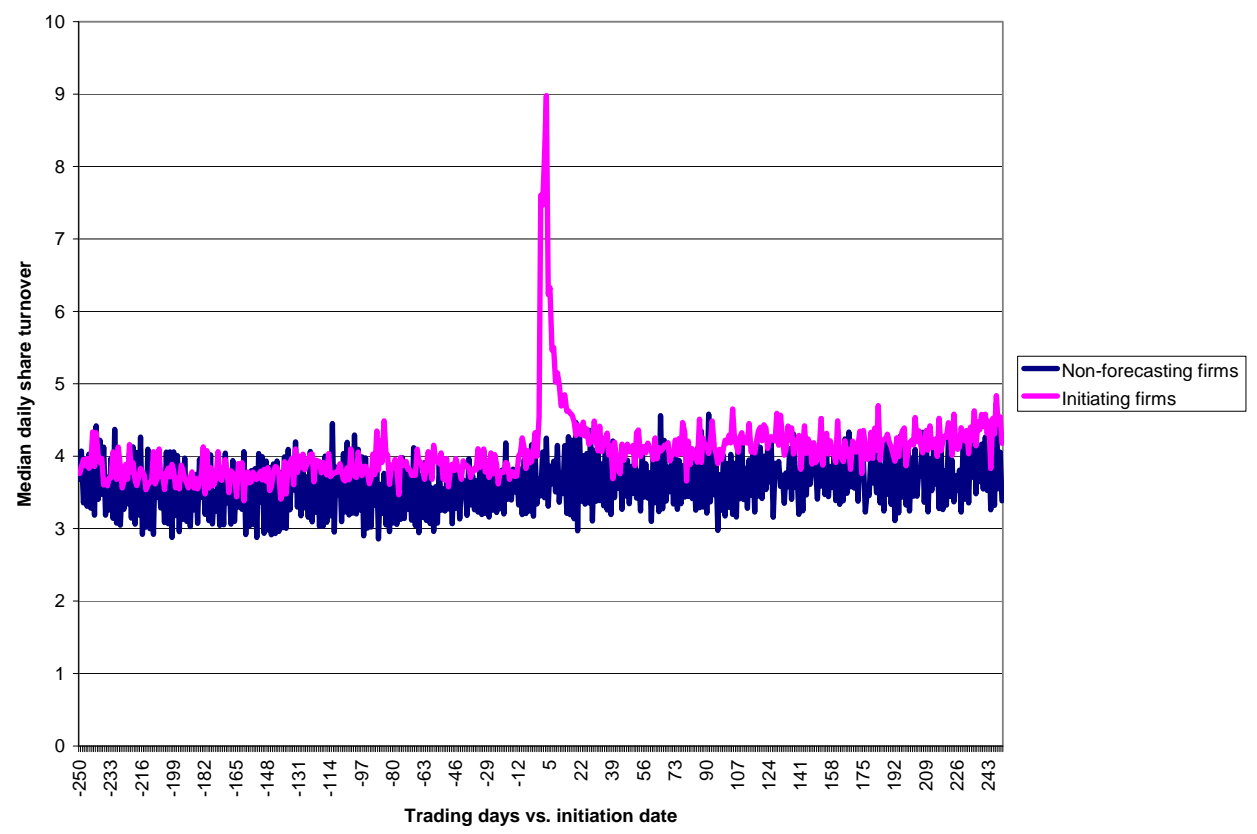


Figure 6A: Quoted bid-ask spreads of stopping firms

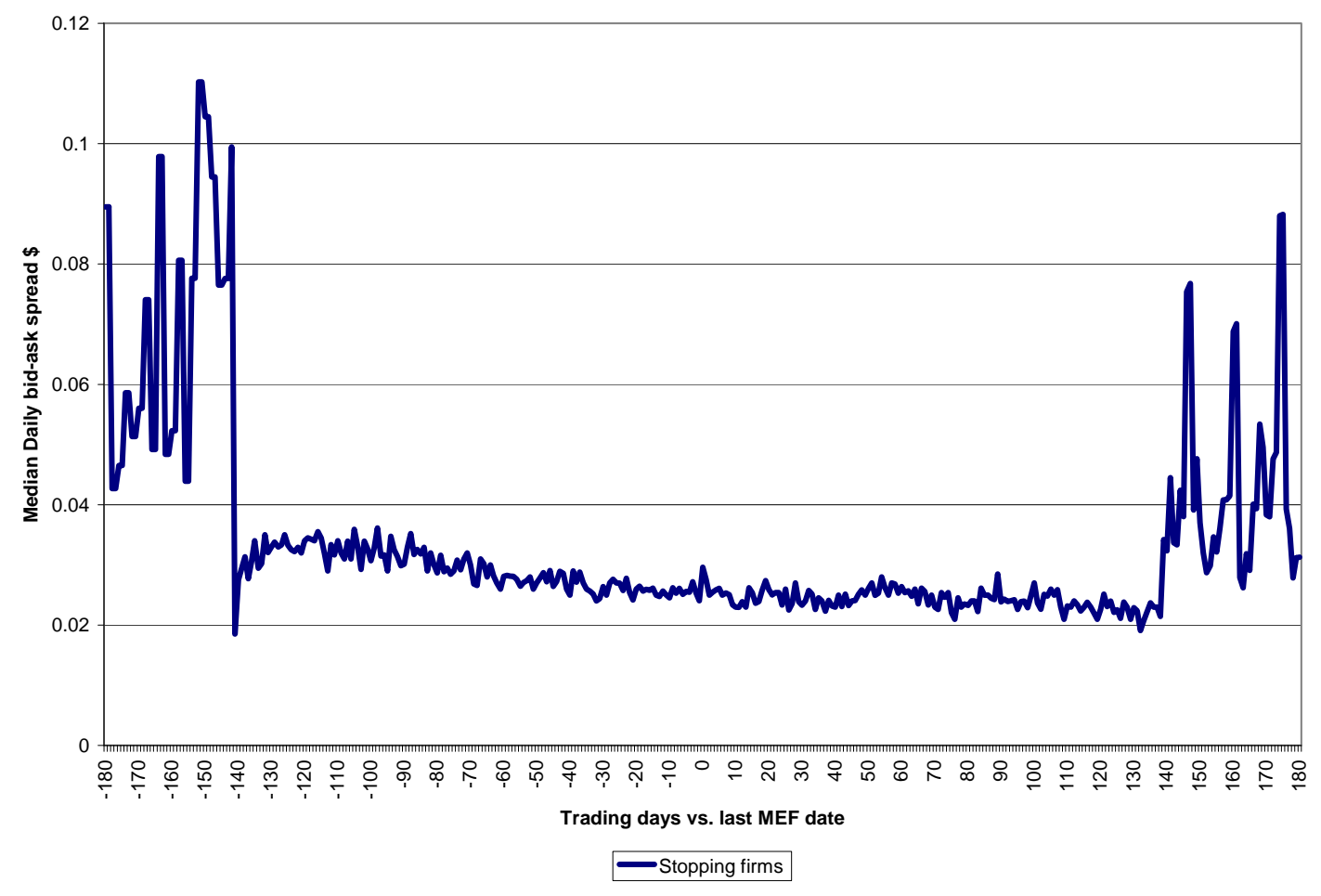

Figure 6B: Quoted depths of stopping firms

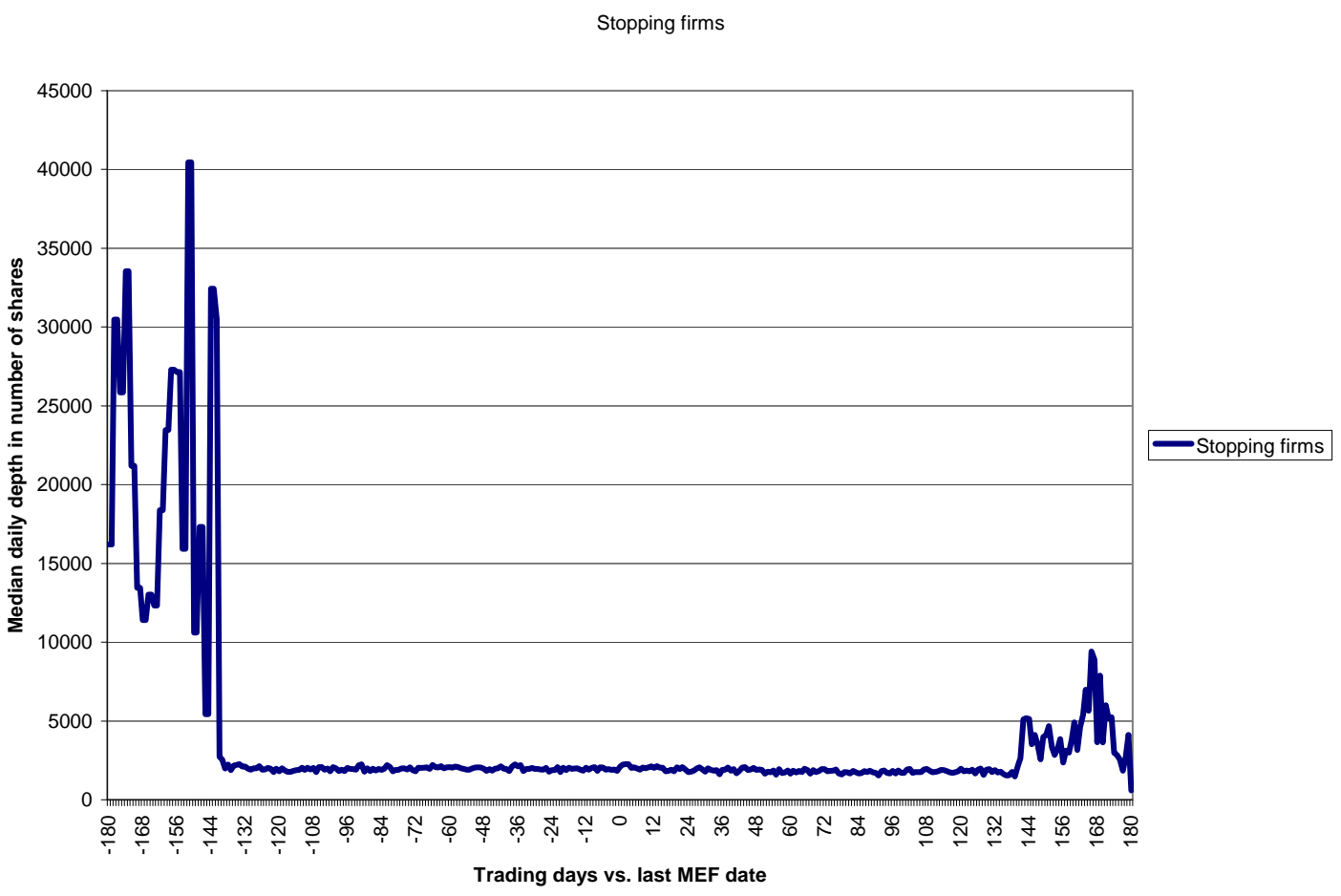


Figure 6C: Amihud Illiquidity of Stopping firms

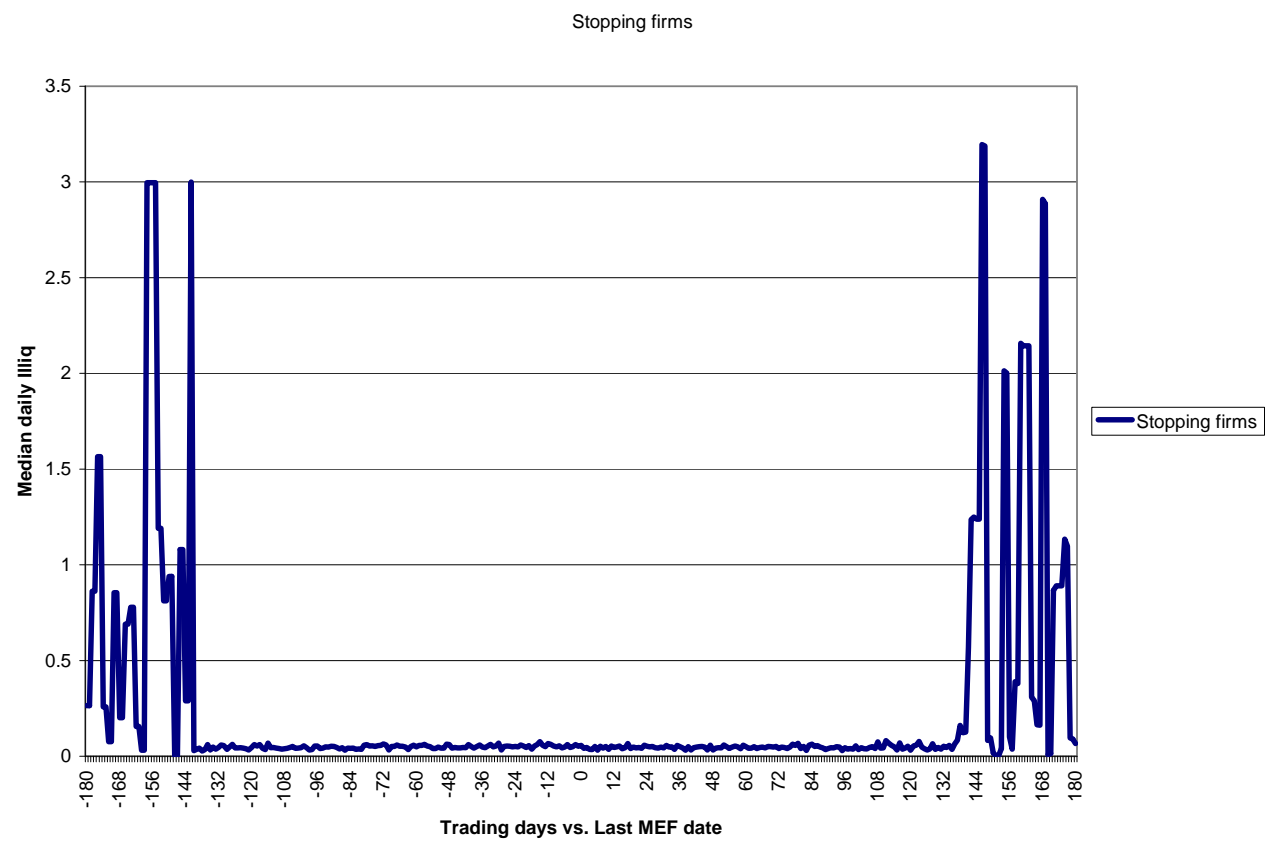

Figure 6D: Share Turnover (volume deflated by shares outstanding) of Stopping firms

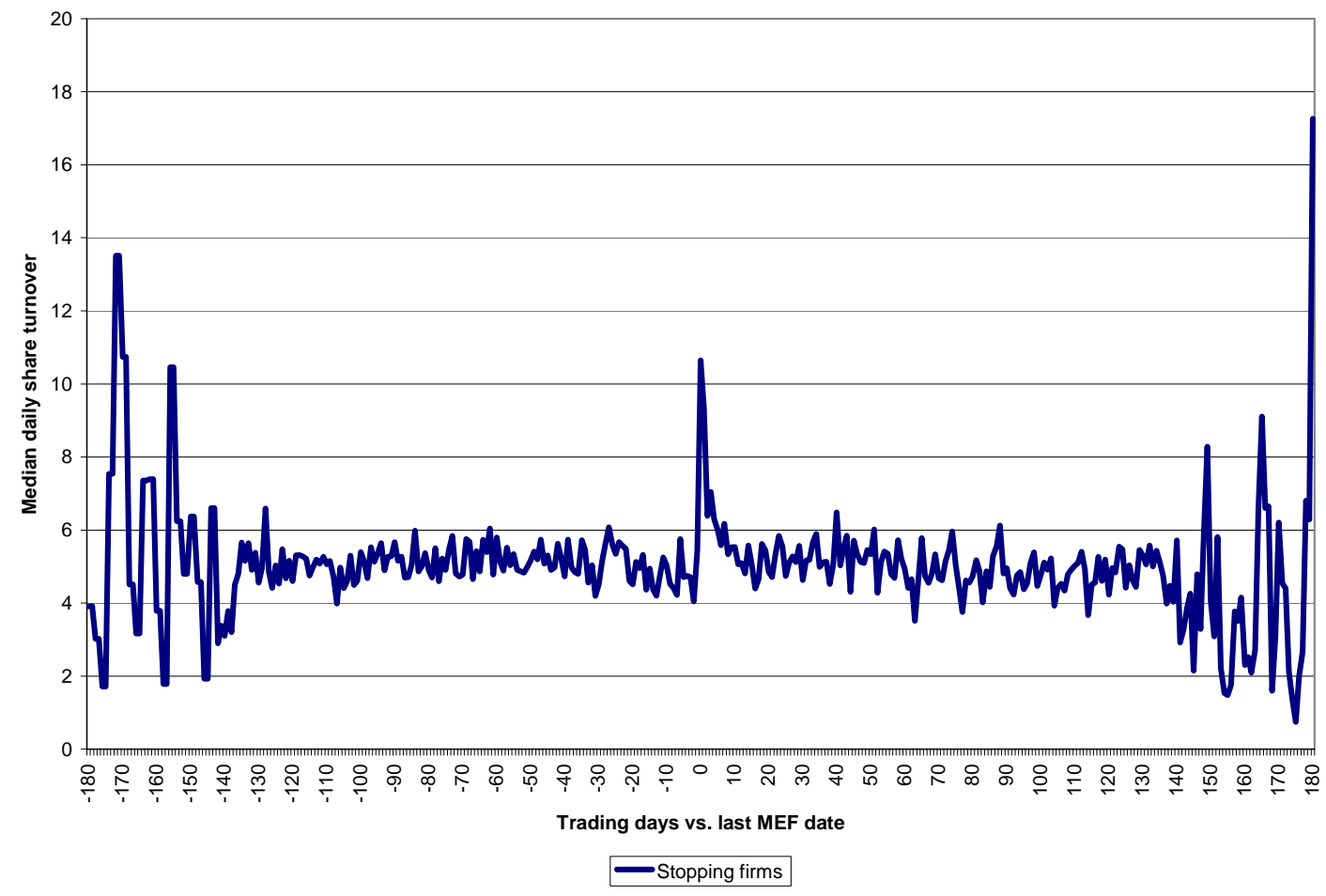

